\title{
EloÁ Francisco Drobina
}

Programa de seguimento semipresencial a novos usuários de prótese auditiva

Dissertação apresentada à Faculdade de Medicina da Universidade de São Paulo para obtenção do título de Mestre em Ciências

Programa de Otorrinolaringologia

Orientador: Prof. Dr. Ricardo Ferreira Bento

SÃO PAULO 
Dados Internacionais de Catalogação na Publicação (CIP)

Preparada pela Biblioteca da

Faculdade de Medicina da Universidade de Sāo Paulo

@reproduçāo autorizada pelo autor

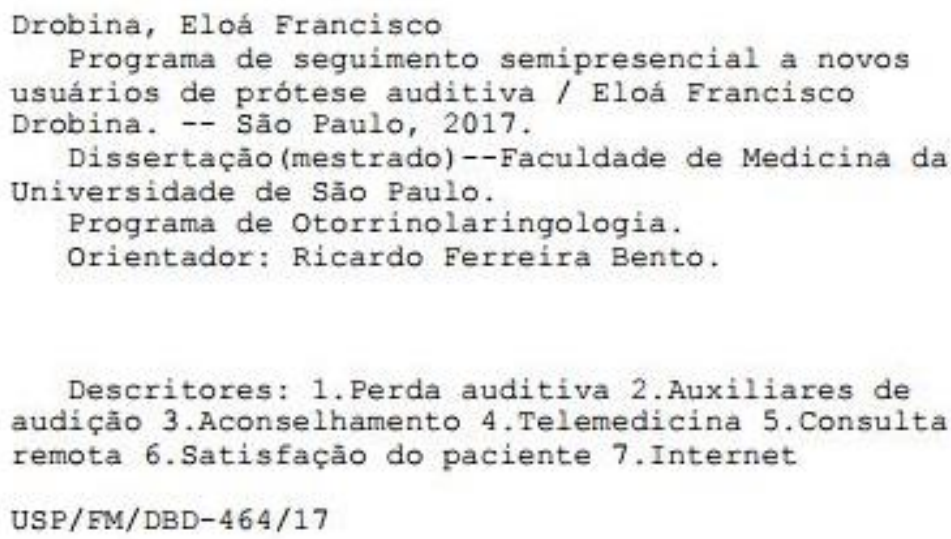




\section{DEDICATÓRIA}

Aos meus pais, Ernesto Drobina (in memorian) e Elizete Francisco Drobina, por desempenhar tão lindamente esse duplo papel que o destino the reservou. Obrigada pela mão estendida, pelo ombro amigo, pelo apoio diário e, especialmente, por estar presente nesse momento tão especial e valioso.

Aos meus irmãos, Erica Francisco Drobina e Lucas Francisco Drobina, e meu querido sobrinho, Enzo Drobina Yadoya, pela compreensão, companheirismo e por estarem ao meu lado durante a minha caminhada.

Aos amigos, Andreza Ferreira, Danilo Euclides Fernandes, Juliana Nanni, Marilda Eleutério e Karina Souza pela amizade sincera, pelo incentivo, apoio e carinho que nutrem por mim. 


\section{AGRADECIMENTOS}

Ao Prof. Dr. Ricardo Ferreira Bento, titular da Disciplina de Otorrinolaringologia do Hospital das Clínicas da Faculdade de Medicina da Universidade de São Paulo, meu querido orientador, expresso meu respeito, admiração e gratidão pelo apoio, paciência, confiança e ensinamentos dedicados nesse período. A alegria e o amor que dedica no exercício da sua profissão que tanto impacta na qualidade de vida das pessoas me inspiram.

À Drâ. Isabela de Souza Jardim, manifesto meu respeito e admiração pessoal e profissional. É muito prazeroso fazer o que amamos quando encontramos pessoas especiais com as quais podemos compartilhar e somar. Agradeço imensamente pelo auxílio, pelo estímulo e por fazer parte da realização desse sonho.

À Prof ${ }^{a}$. Drà. Katia de Almeida, pela disponibilidade, contribuições, reflexões e sugestões enriquecedoras para o aprimoramento deste estudo.

Ao Prof. Dr. Rui Imamura e Dr. Robinson Koji Tsuji, pela disponibilidade, atenção e valiosas contribuições.

Aos meus colegas de trabalho do Centro de Audiologia da Fundação Otorrinolaringologia, por partilharem os momentos desafiadores, as conquistas e por disponibilizarem seu carinho e apoio nesse período.

Ao Adilson Montefusco, pela atenção, gentileza e prontidão na disponibilidade de acesso aos materiais científicos do Centro de Estudos Avançados em Otorrinolaringologia (CEDAO). 
A toda equipe do Ambulatório de Saúde Auditiva da Divisão de Clínica Otorrinolaringológica do Hospital das Clínicas da Faculdade de Medicina da Universidade de São Paulo (Espaço Reouvir), pelo acolhimento e auxílio disponibilizados para a execução deste trabalho.

Aos participantes desta pesquisa, meu sincero agradecimento pela disponibilidade e contribuições essenciais para a realização desta pesquisa.

À Luci e Marilede, agradeço pela cordialidade, delicadeza e paciência durante todo o período deste trabalho. 


\section{Agradecimento Especial}

\section{À Coordenação de Aperfeiçoamento de Pessoal de Nível Superior}

(CAPES), pelo incentivo à pós-graduação e pela concessão de bolsa de estudos para a realização desta pesquisa. 
"A mente que se abre a uma nova ideia jamais voltará ao seu tamanho original."

(Albert Einstein) 
Esta dissertação está de acordo com as seguintes normas, em vigor no momento desta publicação:

Referências: adaptado de International Comittee of Medical Journals Editors (Vancouver).

Universidade de São Paulo. Faculdade de Medicina. Divisão de Biblioteca e Documentação. Guia de apresentação de dissertações, teses e monografias. Elaborado por Anneliese Carneiro da Cunha, Maria Julia de A. L. Freddi, Maria F. Crestana, Marinalva de Souza Aragão, Suely Campos Cardoso, Valéria Vilhena. 3a. ed. São Paulo: Divisão de Biblioteca e Documentação; 2011.

Abreviaturas dos títulos dos periódicos de acordo com List of Journals Indexed in Index Medicus. 


\section{SUMÁRIO}

Lista de abreviaturas e siglas

Lista de figuras

Lista de tabelas

Resumo

Abstract

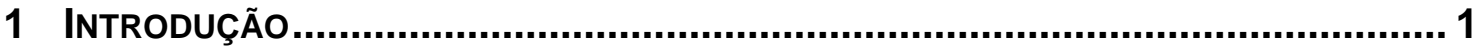

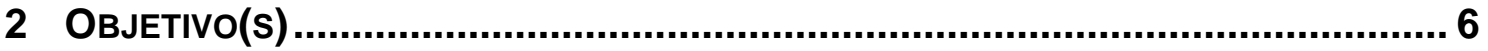

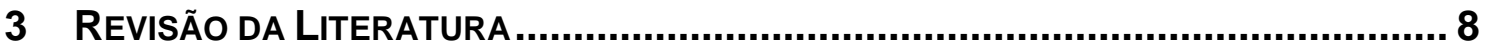

3.1. Telessaúde e Fonoaudiologia ....................................................... 9

3.2. Satisfação com o uso da prótese auditiva por meio do questionário Satisfaction with Amplification in Daily Life (SADL) ................. 18

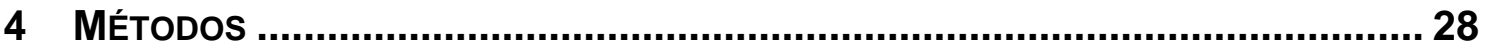

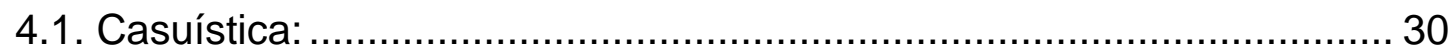

4.1.1. Critérios de inclusão ............................................................. 30

4.1.2. Critérios de exclusão ................................................................. 31

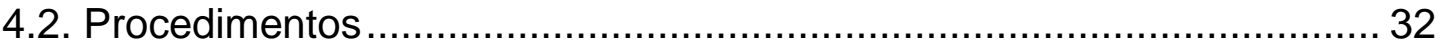

4.2.1 Convocação dos indivíduos para compor a amostra ........................ 32

4.2.2 Etapas do programa ................................................................ 33

4.2.2.1 - 1ㄹ Etapa: Atendimento Presencial .............................................. 34

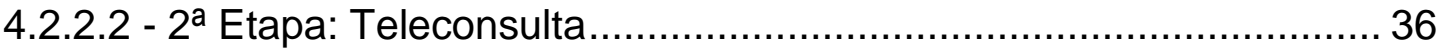

4.2.2.3 - 3 ${ }^{\mathrm{a}}$ Etapa: Atendimento Presencial ........................................... 37

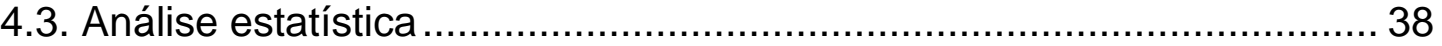

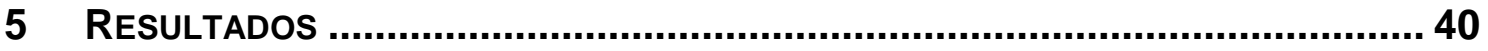

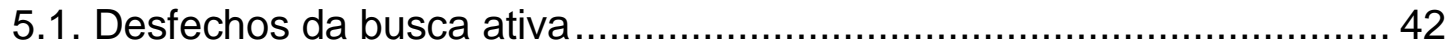

5.2. Análise descritiva da amostra ....................................................... 43

5.3. Análise descritiva das intervenções necessárias nos atendimentos presenciais 
5.4. Análise descritiva das intervenções necessárias nas teleconsultas 47

5.5. Análise descritiva do tempo de uso da prótese auditiva

5.6. Análise descritiva da satisfação com a prótese auditiva por meio do questionário SADL no momento inicial e ao término do programa

5.7. Tempo de duração do programa

5.8. Análise descritiva da avaliação do programa........................................ 50

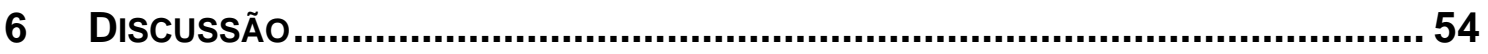

6.1. Caracterização e limitação da amostra ................................................... 55

6.2. Intervenções necessárias durante o programa..................................... 57

6.3. Satisfação com o uso da prótese auditiva por meio do questionário SADL no momento inicial e ao término do programa .................................. 59

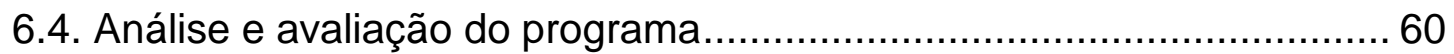

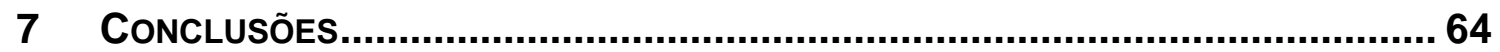

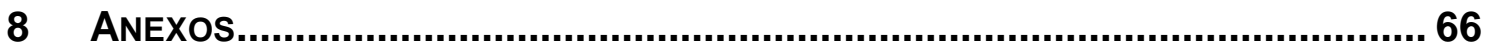

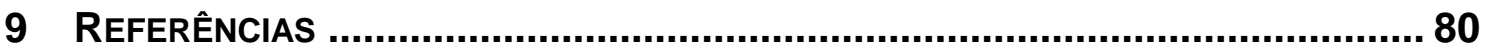




\section{LISTA DE ABREVIATURAS E SIGLAS}

ASHA - American Speech-Language-Hearing Association

dBNA - Decibel em Nível de Audição

DOC - Davis Observation Code

HARL - Hearing Aid Research Laboratories

HHIA - Hearing Handicap Inventory for Adults

HHIES - Hearing Handicap Inventory for the Elderly Screening Version

HINT - Hearing in Noise Test

$\mathrm{Hz}-\mathrm{Hertz}$

IOI-HA - International Outcome Inventory for Hearing Aids

PEQ - Patient Experience Questionnaire

REIG - Real Ear Insertion Gain

SADL - Satisfaction with Amplification in Daily Life

SUS - Serviço Único de Saúde

TCLE - Termo de Consentimento Livre e Esclarecido

TI - Tecnologia da Informação

TIC - Tecnologia da Informação e Comunicação 


\section{LISTA DE FIGURAS}

Figura 1 - llustração das etapas do programa de seguimento

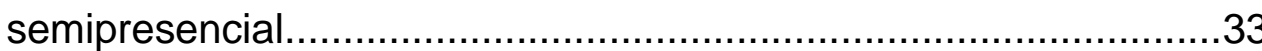

Figura 2 - Desfechos ocorridos na busca ativa dos indivíduos........................42

Figura 3 - Distribuição de número de indivíduos segundo tempo de uso

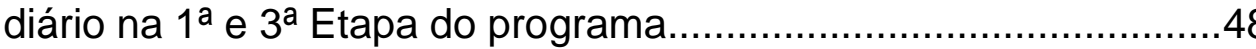




\section{LISTA DE TABELAS}

Tabela 1 - Distribuição de frequências de indivíduos impedidos de aderir ao programa.

Tabela 2 - Caracterização da amostra segundo idade (anos) e sexo 43

Tabela 3 - Distribuição de frequências e porcentagens do Grau de Escolaridade

Tabela 4 - Distribuição de frequências e porcentagens da Ocupação

Profissional. 44

Tabela 5 - Características gerais dos indivíduos em relação ao uso do Skype. .45

Tabela 6 - Comparação ente as variáveis idade e escolaridade em relação ao uso do Skype.

Tabela 7 - Distribuição de frequências das intervenções necessárias nos atendimentos presenciais.

Tabela 8 - Distribuição de frequências das intervenções realizadas e tempo de duração (média) de cada teleconsulta

Tabela 9 - Estatísticas descritivas para a satisfação global e subescalas do questionário SADL nos dois momentos (pré e pós-teleconsulta)....49

Tabela 10 - Medidas descritivas para o tempo (meses) de duração do programa 
Tabela 11 - Distribuição de frequências e porcentagens das respostas ao questionário de avaliação geral do programa

Tabela 12 - Distribuição das respostas obtidas individualmente para a questão

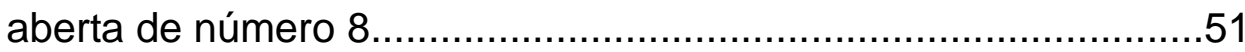

Tabela 13 - Distribuição das respostas obtidas individualmente para a questão aberta de número 9 .52

Tabela 14 - Distribuição das respostas obtidas individualmente para a questão aberta de número 11 .53 


\section{RESUMO}

Drobina EF. Programa de seguimento semipresencial a novos usuários de prótese auditiva [dissertação]. São Paulo: Faculdade de Medicina, Universidade de São Paulo; 2017.

Introdução: As consultas de seguimento com o profissional fonoaudiólogo após a aquisição da prótese auditiva são de extrema importância para a garantia da manutenção do uso com qualidade. As dificuldades enfrentadas pelos usuários no comparecimento ao serviço de saúde impedem que esse processo ocorra de maneira adequada e impactam negativamente no processo de reabilitação auditiva do indivíduo ocasionando, inclusive, o abandono do uso. A incorporação da teleconsulta nesses seguimentos seria uma solução para impedir a ocorrência de tal fato, por permitir que as intervenções de orientações e aconselhamentos sejam realizadas remotamente. Objetivos: desenvolver um programa de seguimento semipresencial para novos usuários de prótese auditiva e verificar sua aplicabilidade. Método: estudo prospectivo (exploratório), no qual dez indivíduos adultos novos usuários de prótese auditiva bilateral, pertencentes a um serviço público de saúde, foram avaliados e submetidos a uma consulta inicial, seguido pela teleconsulta e novamente avaliados numa última etapa presencial. As intervenções realizadas foram classificadas em primárias e secundárias. O questionário para avaliação da satisfação foi aplicado nas etapas presenciais e os dados obtidos pelos registros foram enviados para análise estatística descritiva. Resultados: todos os indivíduos necessitaram de pelo menos uma intervenção na consulta presencial inicial. A maioria esteve relacionada a orientações e aconselhamentos referentes ao uso e manuseio da prótese auditiva (consideradas intervenções secundárias). Na etapa da teleconsulta, todos os indivíduos precisaram de intervenções secundárias, diminuindo sua ocorrência na consulta presencial final. O questionário utilizado para verificar a satisfação apresentou média de escore global com valores de 5,7 na consulta presencial inicial e 6,1 na consulta presencial final, o que correspondeu à satisfação dos participantes. Todos os participantes atribuíram nota máxima ao programa desenvolvido, o que representou a "muito satisfeitos". Conclusão: $O$ estudo traz contribuições para a área da Telessaúde em Fonoaudiologia, pois a utilização das teleconsultas permitiu a resolução de problemas secundários no processo de adaptação à prótese auditiva. Apesar dessa amostra ser reduzida, o estudo inicial foi satisfatório para a continuidade do programa demonstrado ser aplicável. Ainda estudos com maior amostra em diferentes populações são necessários com intuito de validar novos protocolos.

Descritores: perda auditiva; auxiliares de audição; aconselhamento; telemedicina; consulta remota; satisfação do paciente; internet. 


\begin{abstract}
Drobina EF. Follow-up program for new hearing aid users: a combination of inperson and virtual assistance [dissertation]. São Paulo: "Faculdade de Medicina, Universidade de São Paulo"; 2017.

Introduction: Follow-up visits with the audiologist after the hearing aid fitting process are critical to ensure the maintenance of quality use. The difficulties faced by users in adhering to sequential return visits directly affect this process in an inadequate way and negatively impact on individual auditory rehabilitation process, even causing the use abandonment. The inclusion of virtual assistance in these follow-ups would be a solution to avoid this situation, allowing interventions of orientations and counseling by remote consultation. Objectives: to develop a follow-up program combining face-to-face appointments and telehealth for new hearing aid users as well as verifying its applicability. Methods: prospective (exploratory) study evaluated ten new bilateral hearing aid users, seen in a public health service. The first and the last appointments were face-to-face and five followed-ups by virtual assistance. The required interventions were classified as primary and secondary. The questionnaire for satisfaction evaluation were applied during the face-to-face assessments and all registered data was sent for descriptive statistical analysis. Results: all study subjects required at least one intervention during the initial face-to-face visit. Most were related to provide informative counseling and to clarify new users' doubts regarding the use of the hearing aid (considered secondary interventions). At telehealth assistance stage, all subjects required secondary interventions, reducing their occurrence in the final face-to-face assistance. The questionnaire used to verify the satisfaction showed an average overall score of 5.7 in initial stage and 6.1 in the final stage, which proved subjects' satisfaction. All subjects attributed the maximum score to the developed program, which represented "very satisfied". Conclusion: The study contributes to Telemedicine, since the use of virtual assistance allowed the resolution of secondary problems in the hearing aid fitting process. Although this sample was reduced, the initial study was satisfactory for the continuity of this program which has been shown to be applicable. Further studies with larger samples in different populations are needed to validate new protocols.
\end{abstract}

Descriptors: hearing loss; hearing aids; counseling; telemedicine; remote consultation; patient satisfaction; internet. 
1 Introdução

\section{INTRODUÇÃO}

A perda da audição acarreta dificuldades na comunicação, interfere nas relações interpessoais e psicossociais. Uma das ferramentas mais utilizadas para o tratamento de diferentes perdas auditivas é a adaptação de prótese auditiva. Esse sucesso decorre do fato de não ser invasiva e estar disponível em diferentes modelos e tecnologias no mercado. Apesar de ser um importante meio de reabilitação auditiva, estudos revelam o abandono do uso no decorrer do tempo, caso o usuário não realize o acompanhamento periódico após a adaptação da prótese auditiva (Iwahashi et al., 2013).

Como forma de minimizar o abandono do uso, após a seleção e a adaptação da prótese auditiva, o indivíduo usuário precisa estar consciente da importância do comparecimento frequente em consultas com o profissional fonoaudiólogo, assim como o profissional deve estabelecer um protocolo de acompanhamento em seu serviço.

As consultas de acompanhamento que, no presente estudo serão denominadas seguimento, têm como objetivos averiguar itens relacionados aos aspectos anátomo-fisiopatológicos do paciente (excesso de cera e surgimento de doenças), à perda de audição (avaliação da audição), à verificação da prótese auditiva (características eletroacústicas e tecnológicas), além reforçar orientações e aconselhamentos referentes ao uso, manuseio e manutenção da prótese auditiva. Mesmo quando as próteses auditivas são dispendidas pelo 
1 Introdução

serviço público de saúde, faz-se necessário este seguimento (Diretrizes do anexo IV da Portaria MS/SAS no 587,2004 ).

Quando o processo de seguimento não ocorre de maneira adequada, conforme observado, ao longo do tempo, o usuário torna-se insatisfeito com a prótese auditiva, levando à diminuição ou abandono do uso (Goggins e Day, 2009). A satisfação é um fenômeno subjetivo definido pelo usuário que engloba as expectativas, aspectos psicológicos, financeiros, problemas ao longo do processo de reabilitação e dificuldades de comunicação e não depende exclusivamente do bom desempenho da tecnologia (Almeida, 2003; Jardim, 2009). Ela está associada à consciência da própria perda de audição e aos fatores motivadores ao uso da prótese auditiva, que quando descobertos por meio da orientação e aconselhamento, asseguram que o indivíduo atravesse 0 período de adaptação e aclimatização.

A satisfação pode ser avaliada pelo questionário denominado Satisfation with Amplification in Daily Life (SADL) (Hearing Aid Research Laboratories HARL, 2008), validado cientificamente para o português brasileiro (Mondelli et al., 2011). O questionário SADL pode ser utilizado para avaliar o desempenho das próteses auditivas; permitir a documentação e avaliação de determinado programa; sinalizar aspectos relacionados às expectativas dos usuários e necessidades de melhoria específicas para cada caso individualmente (Cox e Alexander,1999).

Tanto no serviço público quanto no privado, os retornos podem ser considerados uma tarefa árdua para o usuário, seja por dificuldades de 
1 Introdução

locomoção; necessidade de presença de acompanhante; adoecimento; falta no trabalho; dificuldades relacionadas à distância; meios de transporte; tráfego urbano; falta de infraestrutura ou outras questões relacionadas às condições de saúde geral do indivíduo (Bento et al., 2015a).

Uma das formas de aumentar a adesão é incorporar a telessaúde nessa rotina, visto que atualmente o acesso à internet por meio de computadores (desktops), notebooks, tablets e smartphones é frequente, atinge ampla faixa etária e acessível nas diferentes classes sociais.

A telessaúde na fonoaudiologia é a prestação de serviços de saúde à distância por meio de tecnologia, pode ser desde uma consulta até um treinamento para outros profissionais da área (American Speech-LanguageHearing Association - ASHA, 2005; CFFa - Resolução no 366, 2009; Ferrari et al., 2010; CFFa - Resolução no 487, 2013). Ela pode ser realizada via protocolos assíncronos (armazenamento e envio) ou síncronos. A teleconsulta síncrona é a que mais se aproxima das consultas presenciais por permitir que profissionais interajam com pacientes ou outros profissionais de saúde utilizando áudio e/ou vídeo em tempo real (Ferrari et al., 2012).

Com o avanço tecnológico, alguns centros de pesquisa iniciaram estudos com o objetivo de incorporar a telessaúde na rotina dos serviços (Penteado et al., 2016) pela necessidade de se comparar os resultados clínicos de sessões presenciais e à distância (Penteado et al., 2012). 
1 Introdução

Nos Estados Unidos, por exemplo, a prática de serviços de telessaúde, no âmbito da prática clínica, já é uma realidade, mas não é unificada nacionalmente. Cada estado possui um estatuto para regulamentação do serviço aos profissionais da área (ASHA, 2016).

No Brasil, este serviço já é amplamente utilizado para educação e treinamento. Contudo, para a prática clínica não existe um protocolo específico com diretrizes de boas práticas para direcionar e guiar o profissional neste serviço.

Tendo em vista a importância do seguimento com um guia de boas práticas para promover um bom resultado da adaptação da prótese auditiva, as dificuldades encontradas pelo usuário para o comparecimento às consultas e o crescimento da telessaúde na área da fonoaudiologia, o objetivo desse estudo é desenvolver um programa de seguimento semipresencial a novos usuários de prótese auditiva verificando a sua aplicabilidade. 
2 Objetivos 
2 Objetivos

2 OBJETIVOS

\section{Objetivo geral:}

- Desenvolver um programa de seguimento semipresencial a novos usuários de prótese auditiva.

\section{Objetivos secundários:}

- Verificar a aplicabilidade do programa de seguimento semipresencial por meio de:

- Identificação das principais dificuldades encontradas pelos indivíduos novos usuários de próteses auditivas que participaram do programa de seguimento semipresencial;

- Verificação da possibilidade de resolução das dificuldades via teleconsulta;

- Aderência ao programa;

- Duração do programa;

- Avaliação do grau de satisfação pela aplicação do questionário SADL e do questionário específico do programa. 
3 Revisão da Literatura 


\section{REVISÃO DA LITERATURA}

Neste capítulo foram abordados dois temas relacionados ao estudo, ambos descritos segundo a ordem cronológica de publicação, a saber:

\subsection{Telessaúde e Fonoaudiologia}

Wen (2008) fez considerações a respeito dos temas Telemedicina e Telessaúde em relação à evolução e consolidação no Brasil desde 2004. A partir do incentivo à pesquisa realizada pelas agências de fomento e com ações governamentais que possibilitaram a formação de equipes e núcleos de pesquisa em diversas instituições universitárias financeiras. Em relação ao avanço da Telemedicina, o autor apontou que além de aspectos tecnológicos, seria uma aplicação efetiva de soluções tecnológicas para fins de otimização da educação, planejamento da logística, regulação da assistência e implementação de métodos para proporcionar pesquisas multicêntricas, baseadas em estratégias de gestão de sustentabilidade e no desenvolvimento de novos recursos. Em seu texto, o autor informou que a evolução tecnológica nas áreas de eletrônica, telecomunicação e computação permitiu acesso a tecnologias que anteriormente tinham custos proibitivos e favoreceu a expansão da aplicação da Telemedicina para diversos serviços de saúde, com o surgimento de termos adicionais tais como Telessaúde / Telehealth, Telecare, e-Health, todos com o objetivo de ampliar a sua abrangência. De acordo com o autor, as atividades da Telemedicina podem ser agrupadas em três grandes conjuntos: Teleducação, com o objetivo de ampliar as 
3 Revisão de Literatura

possibilidades construção de conhecimento; Teleassistência, por meio de desenvolvimento de sistemas para permitir a integração de atividades assistenciais com educação, vigilância epidemiológica e gestão de processos em saúde e por fim, "Teleciência" na qual ocorre a integração de diversos centros de pesquisa.

Swanepoel et al. (2010) fizeram considerações relacionadas à Telessaúde e sua importância no auxílio da formação médica, da interação profissional, no desenvolvimento de pesquisas, na distribuição desigual dos profissionais de saúde que poderiam estar separados por barreiras tais como localização geográfica, climáticas e econômicas no intuito de melhorar a qualidade da prestação de serviço de saúde para a população a nível mundial, principalmente nas áreas mais remotas e carentes. Os autores consideraram o crescimento exponencial da conectividade, no qual um em 4 pessoas no mundo possuíam acesso à internet em 2008. Afirmaram ainda que a Telessaúde pode auxiliar para melhorar e simplificar as práticas atuais, empregando automação, integração e coordenação de processos nos serviços de saúde auditiva na África, assim como em outros países, que não estão disponíveis para a maioria da população por possuir escassez de profissionais treinados, limitações de infraestrutura e recursos. Citaram como exemplo a Teleaudiologia no Brasil e sua abrangência efetiva para profissionais e pacientes. Informaram a respeito da criação de uma organização nãogovernamental, sem fins lucrativos que incorpora serviços de fonoaudiólogos voluntários de países que possuem esses serviços bem estabelecidos para auxiliar em áreas remotas nos quais os mesmos são indisponíveis. 
Penteado e Bento (2011) analisaram as queixas que levariam aos baixos índices de satisfação quanto ao uso da prótese auditiva concedida aos usuários do Sistema Único de Saúde (SUS), tendo em vista o alto investimento governamental para o seu fornecimento e verificaram aspectos relacionados ao paciente (dificuldade no deslocamento ao serviço de saúde), aos fonoaudiólogos (quantidade e complexidade das próteses auditivas que demandariam em treinamentos contínuos / tempo curto para atender todos os usuários que necessitam), às questões ambientais (clínicas credenciadas serem distantes) e aos processos (ausência de suporte técnico online / ausência de plano de treinamento / falta de padronização dos procedimentos). Os autores realizaram trabalhos pioneiros para a implementação da Telemedicina e, por meio de recursos tecnológicos e da internet, as fonoaudiólogas de diferentes unidades de saúde da cidade de São Paulo puderam receber treinamento de uma fonoaudióloga alocada na Unidade Especializada via web, que abordou as características e recursos eletroacústicos de determinada prótese auditiva. Os pacientes, por sua vez, interagiram com as profissionais de ambas as unidades e referiram, subjetivamente, boa amplificação com a prótese auditiva, o que apresentou resultado satisfatório com tal procedimento. Os autores mencionaram a Telemedicina como poderoso aliado para a melhoria da condução das políticas públicas relacionadas à reabilitação auditiva no Brasil, calcadas nos preceitos do conhecimento em geral, da tecnologia existente e da legislação vigente tanto no âmbito governamental pelo Ministério da Saúde quanto no Conselho 
Federal de Fonoaudiologia com a aprovação do uso de tecnologia da informação (TI) considerando suas particularidades para a execução.

Campos e Ferrari (2012) avaliaram a eficácia da teleconsulta para programação, verificação e adaptação da prótese auditiva em 50 indivíduos divididos em dois grupos de 25 , sendo o grupo controle que recebeu consulta face a face e o grupo experimental que recebeu teleconsulta síncrona com vídeo interativo e controle remoto de aplicativos. O tempo para realização da programação bilateral da prótese auditiva, verificação medida com microfone sonda e orientação aos participantes quanto uso diário e cuidados com o dispositivo foi cronometrado. Após as consultas aplicaram o teste de percepção de fala Hearing in Noise Test (HINT). Foi verificado o tempo de uso diário da prótese auditiva, este aspecto está relacionado à adaptação ao som amplificado e às dificuldades auditivas no dia a dia, e aplicação do questionário International Outcome Inventory for Hearing Aids (IOI-HA) aproximadamente após o período mínimo de um mês das consultas. Referiram que os participantes de ambos os grupos exibiram algumas dificuldades quanto ao uso, cuidados e manuseio das próteses auditivas e relataram possibilidade de que 0 aconselhamento informativo realizado à distância não interferiu negativamente em tais habilidades, além de não impactar no tempo de uso das mesmas. As autoras concluíram que embora tenha sido encontrada pequena e não significativa diferença no grau de satisfação entre os grupos, a teleconsulta é um modelo de atendimento eficaz que pode ser utilizada em situações em que exista dificuldade ou impedimento para a realização do atendimento presencial; porém, há necessidade de outros estudos que avaliem as 
perspectivas do paciente quanto ao atendimento via teleconsulta, uma vez que há escassez de literatura na área da audiologia.

Penteado et al. (2012) utilizaram recursos de internet para que fonoaudiólogas do estado de Minas Gerais pudessem receber treinamento da fonoaudióloga do estado de São Paulo por meio de chamada de áudio e vídeo em tempo real via Skype e realizaram os ajustes nas próteses auditivas de três pacientes. Os autores definiram a prática de adaptação de prótese auditiva à distância como Teleaudiologia. Tanto as profissionais quanto os pacientes aprovaram o processo, o que comprovou a possibilidade de realização das ações propostas de maneira remota. Os autores consideraram a possibilidade da implementação da Teleaudiologia no programa de saúde auditiva em conjunto com outras unidades pertencentes ao serviço público de saúde. Afirmaram que apesar da mudança no atendimento presencial para o atendimento à distância exigisse treinamento dos envolvidos, neste caso, otorrinolaringologistas e fonoaudiólogos, que os mesmos não deveriam apresentar resistência à sua utilização, pois os atendimentos presenciais não são descartados. Os pesquisadores sugeriram o desenvolvimento de novos trabalhos relacionados à Teleaudiologia que comparassem resultados clínicos obtidos em sessões presenciais com os obtidos à distância para que as diferenças fossem analisadas e contextualizadas.

Spinardi-Panis et al. (2013) citaram o aumento da utilização de tecnologias de comunicação para diminuir as desigualdades observadas no Brasil, um país com grande extensão territorial. Porém, tendo em vista a 
3 Revisão de Literatura

diversificação das ações em Telessaúde, apontaram a importância do engajamento entre os profissionais fonoaudiólogos juntamente com o conselho desta classe e da sociedade científica no direcionamento da discussão da atuação de ações de Telessaúde em Fonoaudiologia para que as práticas sejam pautadas em critérios éticos e legais.

Penteado et al. (2014) utilizaram o questionário SADL para avaliar a satisfação de usuários de próteses auditivas que foram submetidos à realização de ajustes remotos. Participaram desse estudo piloto oito novos usuários de prótese auditiva, sendo 5 do sexo feminino e 3 do sexo masculino, com idade entre 18 e 90 anos e média de 71,5 anos, que foram selecionados aleatoriamente num serviço público de saúde auditiva da cidade de São Paulo. Nesse estudo, foram realizadas duas sessões presenciais e uma à distância (de até $12 \mathrm{~km}$ entre os dois serviços de saúde pública). Houve intervalos quinzenais entre os dois atendimentos presenciais e o atendimento remoto. Nas consultas presencias foram realizados os procedimentos de consulta com otorrinolaringologista, otoscopia, exames de audiometria e impedanciometria, impressão de pré-molde e primeiros ajustes da prótese auditiva. $\mathrm{O}$ ajuste remoto foi realizado por meio da utilização de Internet com conexão de banda larga, que permitiu o contato entre os profissionais fonoaudiólogos de diferentes locais geográficos, considerados respectivamente pertencentes à unidade especializada (unidade do serviço de saúde auditiva) e o outro, da unidade remota (serviço de saúde pública credenciado). No atendimento via teleconsulta por videoconferência foram realizados ajustes à distância pelo fonoaudiólogo da rede especializada de acordo com a configuração da perda 
3 Revisão de Literatura

auditiva e as possíveis queixas ou relatos apresentados pelos novos usuários de prótese auditiva durante o intervalo de tempo citado, além de fornecer orientações e esclarecimentos pertinentes para cada caso. O fonoaudiólogo presente na unidade remota acompanhou as ações realizadas e por fim, aplicou o questionário SADL que apresentou alto nível de satisfação, com escore médio acima dos encontrados nos dados normativos, semelhante aos obtidos em consultas presenciais. Os autores consideraram a utilização da teleconsulta, no caso, a realização de ajustes da prótese auditiva à distância, como uma sugestão a ser discutida por órgãos públicos para auxiliar na melhoria da prestação de serviços de saúde auditiva, pois permite facilidade e conforto ao usuário, possibilita maior chance de sucesso no processo de reabilitação auditiva, com baixo custo para ser implementada.

Reginato e Ferrari (2014) avaliaram a comunicação profissional-paciente durante o processo de programação e adaptação da prótese auditiva, via teleconsulta e realizaram a comparação da satisfação do paciente em relação à consulta tradicional em 40 novos usuários de prótese auditiva com idade superior a 18 anos. Os participantes foram aleatoriamente divididos em grupo experimental, que realizou procedimento via teleconsulta com utilização do aplicativo Skype, e grupo controle, presencialmente. Após o procedimento de programação e verificação da prótese auditiva, foi aplicado o questionário Patient Experience Questionnaire - PEQ, traduzido e adaptado pelas autoras, pois no momento não havia validação desse questionário no Brasil, com o objetivo de captar respostas mais imediatas, pessoais e afetivas, para avaliar a satisfação dos usuários após a consulta. O conteúdo foi avaliado a partir do 
3 Revisão de Literatura

"Código de Observação de Davis" (Davis Observation Code - DOC) também traduzido pelas autoras para o português brasileiro. A duração das consultas variou de 21,26 a 37,46 minutos no Grupo Controle e de 18,50 a 39 minutos no Grupo Experimental. As autoras afirmam que em média, o tempo despendido para os procedimentos de programação e verificação da prótese auditiva, via teleconsulta foi 5,87 minutos maior do que o das consultas face a face. No que diz respeito à comunicação profissional-paciente, observou-se diferença significativa dos grupos e códigos de comportamento entre as teleconsulta e consultas face a face. Os resultados do PEQ indicaram que apesar de sete participantes do grupo experimental responderam que preferiam a consulta face a face, os resultados apontaram experiências bastante positivas em ambos os grupos; porém, podem ter sido influenciadas pelas preocupações dos pacientes quanto aos impactos de uma resposta negativa, também observado em estudos que avaliam usuários de serviços de audiologia do Sistema Único de Saúde no Brasil. Em relação ao "Código de Observação de Davis", as autoras sugerem pesquisas que utilizem técnicas qualitativas para que a natureza da comunicação profissional-paciente seja mais bem compreendida e intervenções apropriadas sejam aplicadas, visando facilitar a interação mediada pela tecnologia.

Bento e Penteado (2015) utilizaram a telemedicina para desenvolver uma proposta para a terapia de zumbido em indivíduos com ou sem a perda de audição associada. Os autores desenvolveram uma prótese auditiva com gerador de som e por meio de aplicativos gratuitos, o usuário tem acesso ao controle de volume do gerador de som, a qualquer horário e local, sem a 
3 Revisão de Literatura

necessidade do deslocamento do mesmo para o atendimento presencial com o profissional fonoaudiólogo, além da possibilidade de receber aconselhamentos online por áudio ou vídeo para promoção de alívio e conforto ao paciente.

Fonsêca et al. (2015) realizaram revisão sistemática e análise de estudos relativos à telessaúde em fonoaudiologia no Brasil no período entre 2004 a 2014 categorizando-os segundo os níveis de evidência científica apontados pela American Speech-Language-Hearing Association - ASHA (2005). De 172 estudos obtidos na busca inicial, 26 compuseram a revisão sistemática com publicação no ano de 2006 e de 2008 a 2014. Verificou-se que a área de Audiologia esteve presente em 50\% dos estudos avaliados com trabalhos reconhecidos no Brasil e no mundo e a prática da teleducação superou a de teleassistência com índice obtido de $65 \%$ e $35 \%$, respectivamente. Observaram que todos os estudos classificados pertencem essencialmente ao estado de São Paulo, sendo que $92,3 \%$ foram realizados na cidade de Bauru. Este trabalho alertou que a teleducação tem crescido conjuntamente com o desenvolvimento de diversas ferramentas de ensino à distância para diferentes públicos, tornando uma das áreas prioritárias para o desenvolvimento de futuras pesquisas. Para os autores, a Telessaúde em Fonoaudiologia está em plena expansão no Brasil, porém necessita ser ampliada em outras regiões. Observaram que com a evolução das Tecnologias de Informação e Comunicação (TICs), a estruturação e a acessibilidade do fornecimento de cuidados com a saúde encontram-se mais fortalecidas, influenciando na redução das desigualdades observadas na prestação de serviços. Consideraram ainda que as políticas públicas de saúde 
3 Revisão de Literatura

poderiam ser revistas no intuito de garantir saúde para a população de forma mais igualitária.

3.2. Satisfação com o uso da prótese auditiva por meio do questionário Satisfaction with Amplification in Daily Life (SADL)

Cox e Alexander (1999) desenvolveram o questionário SADL no qual a satisfação não envolve apenas o desempenho da prótese auditiva, mas também inclui outras variáveis tais como o serviço profissional e estigma pessoal. Elaboraram inicialmente um questionário com 25 questões e aplicaram em 257 indivíduos. A partir dessas informações desenvolveram o questionário sintetizado com 15 questões, reaplicaram e avaliaram 104 indivíduos. Os autores afirmam que a escala SADL é breve e de fácil preenchimento para pacientes de diferentes graus de escolaridade. As informações extraídas podem ser utilizadas clinicamente para fornecer um índice global de satisfação, documentar e avaliar mérito de determinado programa, além de avaliar as subescalas Efeitos Positivos, Aspectos Negativos, Imagem Pessoal, Custos e Serviços com a finalidade de sinalizar se estão atendendo às expectativas ou apontam necessidade de melhoria para cada paciente individualmente.

Jardim (2009) elaborou um protocolo de adaptação de prótese auditiva com o exame de verificação de mapeamento de fala que tinha como objetivo verificar as características da amplificação e orientar o usuário. Foram 
3 Revisão de Literatura

analisados 60 novos usuários de tecnologia digital básica, intermediária e avançada de um serviço público de saúde auditiva. Estes indivíduos, separados em dois grupos, tiveram como fator diferencial um grupo ter recebido orientação e outro não. Quando aplicado o SADL, antes e depois do processo, foi observada diferença na análise estatística quando realizada separada por grupo e na comparação entre os dois grupos. No grupo que não recebeu orientação, o score global de satisfação foi maior na tecnologia básica e menor que o score do grupo que recebeu orientação. No entanto, no grupo que recebeu orientação, não houve diferença na satisfação dentro do grupo independentemente da tecnologia.

Farias e Russo (2010) avaliaram a variável satisfação por meio da utilização do questionário SADL e a influência das características dos serviços recebidos associados ao uso das próteses auditivas, ao acolhimento e acompanhamento da adaptação. Participaram do estudo 39 indivíduos do estado da Bahia novos usuários de próteses auditivas atendidos em serviços de saúde auditiva vinculados ao Sistema Único de Saúde (SUS) com idade entre 18 e 90 anos, média de idade de 58,23 anos, e período mínimo de quatro semanas e máximo de 12 após o início da adaptação. Constataram que os elevados índices de satisfação encontrados após aplicação do questionário em todos os participantes da pesquisa, foram maiores do que o encontrado na normatização. Para este fato, os autores atribuíram a hipótese de que a variável satisfação é influenciada pelas características dos serviços prestados, que englobam acolhimento recebido, vínculo estabelecido e responsividade do sistema. Ainda exemplificaram a afirmativa pelo fato dos entrevistados 
3 Revisão de Literatura

atribuírem pontuações máximas, ou seja, 6 e 7, para as questões da categoria serviço e custo do questionário. Os autores correlacionaram os achados às variáveis: sexo, idade, grau de perda auditiva, tipo e perfil eletroacústico das próteses auditivas. Apenas em relação ao tipo, os usuários de modelos intraaurais mostraram-se mais satisfeitos do que os de modelo retroauriculares.

Magalhães e Mondelli (2011) realizaram revisão sistemática de dezenove artigos relacionados à questão única genérica: "O questionário SADL é útil para avaliar a satisfação dos usuários de prótese auditiva?" Os autores constataram que alguns estudos indicaram que o efeito positivo teria forte influência na construção da satisfação; informaram que algumas pesquisas apontaram a questão 15, sobre o conserto da prótese auditiva, como uma limitação do questionário, visto que é difícil de ser avaliado por indivíduos com pouco tempo de adaptação; verificaram que a aplicação do questionário seria mais eficaz após um mês ou seis semanas de adaptação. Os autores observaram ainda que a dificuldade ao uso do telefone foi considerada uma das queixas mais importantes durante a aplicação do SADL e apontaram a necessidade de mais orientações com relação ao uso e manuseio da prótese auditiva. Na opinião das autoras, o estudo apresentou bom desempenho para identificar a eficácia do questionário após um período de aclimatização com a amplificação além de ser um instrumento de fácil compreensão, rápida aplicabilidade e voltado ao uso clínico, podendo ser considerado como avaliação ouro para obter resultados sobre a satisfação do usuário de AASI. 
3 Revisão de Literatura

Laperuta e Fiorini (2012) analisaram a satisfação de 22 idosos, com idades entre 63 e 87 anos, em um serviço de alta complexidade na cidade de São Paulo pela aplicação do questionário SADL no dia da adaptação das próteses auditivas e nos retornos de um, três e seis meses do paciente à instituição. Os resultados indicaram melhora no escore global nos primeiros três meses de uso e o resultado se manteve aos seis meses, assim como o aumento do escore dos efeitos positivos no mesmo período de tempo. Em relação aos fatores negativos, observaram aumento do escore a partir de seis meses de uso. As autoras apontaram a importância de pesquisas longitudinais com utilização de instrumentos de avaliação como possibilidades de auxiliarem a prática clínica, principalmente na assistência para uma melhor adaptação de prótese auditiva.

Buriti e Oliveira (2012) avaliaram 32 usuários de próteses auditivas, com idade entre 21 e 95 anos e tempo de aquisição mínimo de seis meses. As próteses auditivas foram fornecidas por meio do Sistema Único de Saúde (SUS) e o estudo foi realizado pelo Serviço de Reabilitação Auditiva de um complexo hospitalar vinculado ao Programa de Atenção à Saúde Auditiva do município de João Pessoa (PB). As autoras utilizaram dois questionários: o primeiro com questões relativas ao perfil sócio demográfico, ao uso e manuseio das pilhas, dos moldes auriculares ou cápsula e cuidados com o circuito da prótese. O segundo, International Outcome Inventory for Hearing Aids (IOI-HA) para realizar medidas de auto avaliação em reabilitação auditiva. Além de avaliar a adaptação das próteses auditivas, as autoras tiveram como objetivo propor ações educativas em serviço a partir das necessidades observadas. 
3 Revisão de Literatura

Neste estudo, os participantes apresentaram dificuldades em relação ao uso e manuseio das próteses auditivas, aspectos que influenciaram negativamente à adaptação com as mesmas. Devido a esses resultados, as autoras referem a importância da promoção de ações educativas em saúde auditiva para favorecer a capacitação dos usuários e minimizar as dificuldades de adaptação às próteses auditivas.

Aurélio et al. (2012) aplicaram o questionário SADL em 60 indivíduos, com idade entre 18 e 91 anos, portadores de perda auditiva sensorioneural ou mista bilateral, novos usuários de próteses auditivas fornecidas em um serviço de alta complexidade do Sistema Único de Saúde (SUS), por um período mínimo de duas semanas com o objetivo de correlacionar a satisfação do paciente com a idade, sexo, tempo de uso diário e tipo da prótese auditiva. Observaram que os participantes apresentaram-se muito satisfeitos, com escore médio global de 5,9 e apresenta-se acima de valores preconizados pelos autores do questionário. Atribuíram essa pontuação pelo fato das subescalas Custos e Serviços e Efeitos Positivos apresentarem valores elevados pelo fato dos indivíduos terem sido beneficiados gratuitamente com as próteses auditivas e estarem satisfeitos em relação à qualidade do som e melhora da comunicação, respectivamente. Neste estudo, os autores afirmam que o SADL provou ser um instrumento eficiente e preciso para avaliar o nível de satisfação dos usuários de próteses auditivas. Nos resultados, não encontraram relação com as variáveis estudadas; porém, observaram diferença significativa entre a satisfação global, a subescala Imagem Pessoal e a variável tempo de uso diário com valor médio maior nos indivíduos que relataram 
3 Revisão de Literatura

utilizar as próteses auditivas entre 8 e 16 horas diárias comparados aos que relataram entre 4 e 8 horas diárias. Ainda sugerem que haveria possibilidade da correlação da satisfação nas subescalas Efeitos Positivos, Custos e Serviços com a variável tempo de uso diário apresentar diferença significativa caso a amostra fosse maior.

Silva et al. (2013) utilizaram os questionários Hearing Handicap Inventory for Adults (HHIA) e Hearing Handicap Inventory for the Elderly Screening Version (HHIES) para avaliar o benefício com a prótese auditiva e o questionário SADL após um mês de adaptação para avaliar a satisfação em 34 indivíduos novos usuários de próteses auditivas com idade superior a 18 anos em um serviço credenciado ao Sistema Único de Saúde (SUS) no estado de Rondônia. Os resultados do questionário SADL sugerem alto grau de satisfação em todas as subescalas bem como no escore global $(6,8)$. As médias calculadas mostraram-se superiores aos valores encontrados pelos autores do questionário e em outros estudos que utilizaram o mesmo instrumento. Os mesmos justificam este achado pelo fato dos indivíduos terem sido beneficiados pela concessão de próteses auditivas pelo SUS juntamente ao contentamento com o atendimento recebido. Além disso, os autores sugerem que a melhora evidenciada no primeiro mês após a protetização gera maior satisfação do que a mensurada após muitos meses de utilização das próteses auditivas. Neste estudo não foi verificada diferença significativa no grau de satisfação entre os grupos adultos e idosos. Na opinião dos autores, a satisfação é influenciada pelo benefício percebido, abrangendo aspectos como expectativas dos usuários, custos financeiros e psicológicos envolvidos, 
3 Revisão de Literatura

problemas encontrados durante a reabilitação e as dificuldades de comunicação.

Iwahashi et al. (2013) avaliaram 200 sujeitos após um ano de uso de próteses auditivas fornecidas por um serviço público de saúde na cidade de São Paulo. Utilizaram o questionário SADL para analisar a satisfação e realizaram o registro de intervenções necessárias. Neste estudo, 97,49\% dos usuários de próteses auditivas apresentaram altos índices de satisfação tanto no escore global, com pontuação média de 6 , quanto nas subescalas. Em relação às intervenções, 99,5\% dos usuários precisaram de alguma forma de intervenção após um ano de uso, sendo que 40,5\% tiveram problemas substanciais com suas próteses auditivas. Um aspecto a ser enfatizado nesse estudo seria a observação de que as intervenções mais recorrentes estavam relacionadas a procedimentos de orientação e aconselhamento. Os autores apontaram a dificuldade de comparecimento dos usuários às consultas de seguimento no serviço público de saúde, o que afeta a efetividade de longo prazo da reabilitação auditiva.

Dell Antonia et al. (2013) aplicaram o questionário SADL em 180 indivíduos, idade de 14 a 94 anos, usuários de próteses auditivas durante o período de 30 dias de adaptação, atendidos no serviço de saúde de Hospital Universitário da Universidade Federal de Santa Catarina (HU-UFSC). As variáveis analisadas foram: idade, sexo, escolaridade, tipo de perda auditiva em cada orelha, grau da perda auditiva, tipo de prótese auditiva, tempo de uso das próteses auditivas, tempo diário de uso, presença de comorbidades e grau 
de satisfação com as próteses auditivas. O grau de satisfação global dos pacientes evidenciou satisfação com o uso das próteses auditivas, média de escore global 5,6 (173 participantes). A subescala Imagem Pessoal revelou mais insatisfação nos pacientes com perda auditiva neurossensorial e perda auditiva de grau profundo. Quanto ao tipo da prótese auditiva, observaram que as próteses auditivas do tipo intra-auriculares estiveram relacionadas a graus mais elevados de satisfação. Os autores sugerem novos estudos em um período maior de observação a fim de obter novos e úteis dados em relação à avaliação da protetização auditiva.

Bento et al. (2015) realizaram um estudo piloto com 20 usuários de prótese auditiva atendidos em um serviço público de saúde credenciado pelo SUS (Reouvir). Primeiramente, os autores aplicaram o questionário SADL para avaliar a satisfação subjetiva de usuários de prótese auditiva e compararam com os resultados da amplificação da prótese auditiva verificados objetivamente por meio de ganho efetivo de inserção de ouvido real (REIG). Os autores consideraram ambos como ferramentas importantes que devem ser utilizadas conjuntamente como parte do protocolo na rotina do serviço de reabilitação auditiva.

Peruzzo et al. (2015) aplicaram o questionário SADL em 50 pacientes, com idade entre 17 e 84 anos, que receberam próteses auditivas via SUS, 30 dias após o recebimento das mesmas e reaplicaram o mesmo questionário após 60 dias de adaptação. As variáveis faixa etária, grau de perda auditiva e tipo de prótese auditiva foram analisadas pela comparação entre as médias de 
3 Revisão de Literatura

pontuação da primeira e segunda aplicação do questionário em relação às subescalas Efeito Positivo, Fator Negativo, Serviço e Custo e Imagem Pessoal. Os autores constataram a necessidade de ajuda dos aplicadores para que os participantes pudessem compreender a maioria das questões contidas no questionário SADL, apesar de ser descrito como um questionário prático e de fácil entendimento. Como resultado, de maneira geral, observou-se melhora dos resultados em todas as subescalas entre a primeira e a segunda avaliação. Os autores apontam a subescala Efeito Positivo como a de maiores números de satisfação em relação às variáveis estudadas. Quanto à faixa etária, $60 \%$ dos sujeitos com idade superior a 60 anos apresentou diferença significante entre a análise dos resultados da primeira e segunda avaliação desta subescala. Em relação ao grau de perda auditiva, 38\% dos sujeitos com perda auditiva de grau moderado e $32 \%$ com grau moderadamente severo obtiveram melhora significante na mesma escala citada acima. Pela análise do tipo de prótese auditiva, os usuários de próteses tipo A apresentaram maior grau de satisfação, com diferença estatisticamente significante. Os autores também informaram que a maioria dos participantes da pesquisa referiu insatisfação com uso de telefone, aspecto que influencia a subescala Fatores Negativos.

Almeida et al. (2016) utilizaram o questionário SADL com pacientes que foram submetidos a ajustes em suas próteses auditivas por meio do ganho funcional e compararam as respostas obtidas quando reaplicaram ao retorno dos usuários no serviço de saúde após a implementação da realização de ajustes por meio do método objetivo pela utilização do ganho efetivo de inserção em orelha real (REIG). Os autores afirmaram ter utilizado o 
3 Revisão de Literatura

questionário SADL pela importância em ser validado além de permitir a comparação de resultados de satisfação como ferramenta para analisar a viabilidade de propostas de melhorias do serviço e o impacto no usuário. 
4 Métodos 
4 Métodos

\section{MÉTODOS}

Estudo prospectivo (exploratório), em adultos novos usuários de prótese auditiva, realizado em um serviço público de saúde do município de São Paulo (Espaço Reouvir, ambulatório de saúde auditiva da Divisão de Clínica Otorrinolaringológica do Hospital das Clínicas da Faculdade de Medicina da Universidade de São Paulo) no período compreendido entre julho de 2015 a agosto de 2017.

Essa pesquisa foi aprovada pela da Comissão de Ética para Análise de Projetos de Pesquisa (CAPPesq) da Diretoria Clínica do Hospital das Clínicas e da Faculdade de Medicina da Universidade de são Paulo conforme resolução do Conselho Nacional de Saúde no 196 de 10/10/1996, pelo registro online 12974, de 28/01/2015 (Anexo A). Somente foram incluídos nesse estudo os indivíduos que autorizaram a participação voluntária, após a explicação completa sobre a natureza do estudo, seus objetivos, métodos, riscos e sigilo quanto à identificação. O responsável ou o próprio sujeito assinou o termo de Consentimento Livre e Esclarecido (Anexo B). 
4.1. Casuística:

Participaram da pesquisa dez novos usuários de prótese auditiva modelo retroauricular, de tecnologia digital bilateral, atendidos em um serviço público de saúde do município de São Paulo.

\subsubsection{Critérios de inclusão}

Para a composição da amostra foram elencados os seguintes critérios de elegibilidade:

- Adultos com idade acima de 18 anos;

- Ambos os sexos;

- Portadores de perda auditiva neurossensorial bilateral de grau leve a moderadamente severo, isto é, com média dos limiares audiométricos das frequências de 500, 1000, $2000 \mathrm{~Hz}$ entre 25 e 70 dBNA (Loyd e Kaplan, 1978);

- Perda auditiva adquirida no período pós-lingual (Oliveira et al., 2002);

- Novos usuários de prótese auditiva que haviam recebido e completado o processo de adaptação no período compreendido entre 30 e 50 dias de aquisição; 
4 Métodos

- Novos usuários de prótese auditiva de tecnologia digital de plataforma básica, intermediária ou avançada, com amplificação digital não linear em ambas as orelhas;

- Possuir computador e internet para acesso às teleconsultas síncronas.

\subsubsection{Critérios de exclusão}

Foram excluídos os sujeitos que não atendiam aos critérios de inclusão mencionados anteriormente ou que apresentaram ao menos um dos itens elencados abaixo:

- Alterações cognitivas, neurológicas ou síndromes associadas;

- Dificuldade motora ou visual grave;

- Perda auditiva flutuante;

- Não ter habilidade para o uso do computador e/ou não ter auxílio de um familiar;

- Não comparecer ao menos em uma das cinco sessões de teleconsulta previamente combinadas e agendadas. 
4.2. Procedimentos

4.2.1 Convocação dos indivíduos para compor a amostra

Para o estudo, foi realizada a busca de informações nos prontuários para verificação dos critérios de inclusão e exclusão dos possíveis candidatos. De acordo com a análise de prontuários, foram selecionados 252 indivíduos novos usuários de prótese auditiva para realização da busca ativa por contato telefônico, realizado em diferentes horários do dia e tentativas de até cinco chamadas telefônicas nos números cadastrados nos prontuários. Considerouse impossibilidade de contato telefônico a ocorrência de número inexistente, incorreto ou ligação não atendida após as tentativas supracitadas.

Quando o contato telefônico foi realizado com êxito, a pesquisadora explicou aos indivíduos ou seus responsáveis a proposta geral do projeto de pesquisa e confirmou os critérios específicos para realização do estudo que não estavam expostos nos prontuários dos indivíduos pré-selecionados, tais como: possuir computador em casa, ter ou não habilidade para o uso do mesmo - quando a resposta fosse negativa, foi questionada a possibilidade de um familiar que pudesse auxiliá-lo - e possuir acesso à internet. Posteriormente à verificação da probabilidade de execução do programa de seguimento semipresencial a novos usuários de prótese auditiva, foi realizada a explicação da proposta do estudo, seus objetivos, procedimentos e o convite à participação. 
Quando houve o aceite à participação, foi realizado o agendamento do atendimento presencial no serviço de saúde ao qual estavam vinculados e a confirmação da presença no dia anterior à consulta previamente agendada, com intuito de reduzir a quantidade de absentismo.

Os indivíduos que não puderam participar por pertencerem aos critérios específicos investigados no contato telefônico (questões relacionadas ao uso do computador e acesso a internet), ou aqueles que se recusaram a participar do estudo, foram questionados a opinar a respeito da proposta do programa e os possíveis motivos da recusa para que fossem registrados.

\subsubsection{Etapas do programa}

Este programa de seguimento semipresencial foi composto por três etapas, conforme ilustrado na Figura 1, e descritas a seguir:

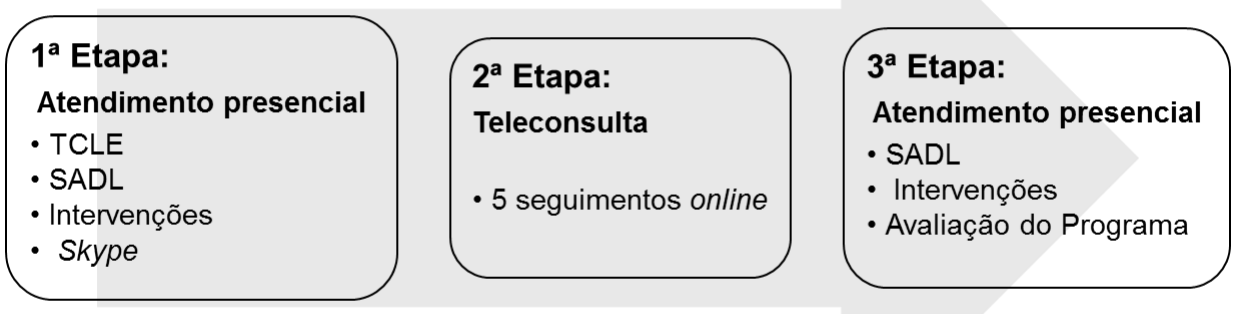

Figura 1 - llustração das etapas do programa de seguimento semipresencial 


\subsubsection{1 - 1 ${ }^{\text {a }}$ Etapa: Atendimento Presencial}

Após as explicações detalhadas relacionadas ao projeto desenvolvido e a coleta da assinatura do Termo de Consentimento Livre e Esclarecido (Anexo B), os indivíduos foram submetidos aos seguintes procedimentos:

- Aplicação do questionário Satisfaction with Amplification in Daily Life - SADL

O questionário SADL (Anexo C) validado para o português brasileiro foi aplicado em forma de entrevista pela própria pesquisadora, o que permitiu 0 esclarecimento de possíveis dúvidas ocorridas durante sua utilização (Mondelli et al., 2011).

O mesmo consiste em quinze questões divididas em quatro subescalas: Efeitos Positivos nas situações de vida diária (seis itens associados com o benefício acústico e psicológico), Serviços e Custos (três itens associados com competência profissional, preço do produto e número de consertos), Fatores Negativos ao uso da prótese auditiva (três itens relacionados com a amplificação de ruído ambiental, a presença de retroalimentação e o uso do telefone) e Imagem Pessoal (três itens relacionados com fatores estéticos e o estigma do uso da prótese auditiva). Em cada uma das questões, o indivíduo classifica suas respostas entre sete alternativas: não, muito pouco, pouco, médio, às vezes, quase sempre e sempre (Mondelli et al., 2011). Para cada alternativa, há uma pontuação atribuída que pode variar de um a sete, sendo sete, o grau máximo de satisfação. Especificamente para as questões de

número 2, 4, 7 e 13 essa análise é invertida, sendo considerada pontuação 
4 Métodos

máxima para a alternativa "não" e mínima para a alternativa "sempre". Para análise dos resultados considera a média aritmética simples obtida nas quinze questões para a satisfação global, assim como a média aritmética simples obtida em cada uma das quatro subescalas. Para classificação de satisfação global, quanto maior a pontuação obtida, maior a satisfação do indivíduo com relação ao uso da prótese auditiva. (Cox e Alexander, 1999).

Após a aplicação do questionário SADL, a pesquisadora realizou a inspeção de meato acústico externo, verificou as condições da prótese auditiva e seus componentes, interrogou os novos usuários em relação às queixas, às possíveis dúvidas relacionadas ao uso e manuseio da prótese auditiva e registrou todas as intervenções que foram necessárias.

- Registro das intervenções presenciais necessárias

Para o registro das intervenções presenciais foi elaborado um protocolo semiaberto, ou seja, um roteiro adaptado de acordo com o estudo de Goggins e Day (2009) e o registro das dúvidas referidas individualmente foi apontado pela pesquisadora no item denominado "Outros" (Anexo D).

Este protocolo define intervenções primárias (realização de audiometria, inspeção de meato acústico externo) e secundárias (orientações relacionadas ao uso de telefone com a prótese auditiva, explicações sobre inserção do molde auricular, entre outros) considerando o aprofundamento na intervenção. No seguimento presencial são realizadas as intervenções primárias e secundárias. 
- Orientação para instalação e uso do software Skype (Anexo E)

Ao final do seguimento presencial, os indivíduos receberam orientações em relação à instalação e ao uso do software Skype, foram agendados para o primeiro atendimento online e liberados. O Skype foi selecionado como ferramenta para a realização da teleconsulta síncrona pelo fato de ser gratuito e permitir a execução de chamadas de áudio e vídeo em tempo real.

\subsubsection{2 - 2 ${ }^{\mathrm{a}}$ Etapa: Teleconsulta}

Nesta etapa, foi realizado o total de cinco teleconsultas síncronas. Em cada um desses seguimentos online, foram efetuadas apenas as intervenções secundárias, de orientações e aconselhamentos, com intervalos que variaram entre semanais e mensais, de acordo com a necessidade e disponibilidade de cada indivíduo. A proposta de duração de cada teleconsulta foi de 20 a 30 minutos.

No dia anterior ao agendamento da teleconsulta, a pesquisadora confirmou a participação dos indivíduos por meio de contato telefônico ou via mensagem por whatsapp. No momento da consulta via web, a pesquisadora questionou os participantes em relação aos esclarecimentos fornecidos anteriormente, com a finalidade de averiguar a compreensão e retenção da informação fornecida e realizou as novas intervenções que foram necessárias.

Ao final de cada seguimento online, os aspectos discutidos foram anotados individualmente no registro das intervenções da teleconsulta, 
4 Métodos

estruturado de maneira semiaberta, a qual possibilitou que os participantes expressassem suas dúvidas pontuais (registradas pela pesquisadora no item “Outros"), adaptado de acordo com o estudo de Goggins e Day (2009), (Anexo F).

Ao término do último seguimento online considerou-se a $2^{\underline{a}}$ Etapa como concluída e os indivíduos foram agendados para o atendimento presencial, ou seja, para a 3ª Etapa do programa.

\subsubsection{3 - 3ㄹ Etapa: Atendimento Presencial}

Nesse seguimento presencial, foram realizados:

- Registro das intervenções necessárias (primárias e secundárias), após realização das ações de acordo com o exposto na 1를 Etapa;

- Reaplicação do questionário SADL, conforme descrito na $1^{\underline{a}}$ Etapa;

- Aplicação do "Questionário de avaliação geral do programa" (Anexo G).

O "Questionário de avaliação geral do programa" foi desenvolvido pela própria pesquisadora. Esse questionário era composto por oito questões fechadas, nas quais foram previamente definidas as alternativas que pudessem ser assinaladas (medidas quantitativas), e três questões abertas, para que o indivíduo pudesse responder livremente a fim de serem obtidas opiniões, 
4 Métodos

sentimentos e reações (medidas qualitativas) frente à experiência via teleconsulta.

O questionário de avaliação geral do programa foi aplicado sem a presença da pesquisadora com o intuito de permitir a liberdade do indivíduo em expressar sua opinião de maneira confortável. Após a entrega e solicitação de seu preenchimento, a pesquisadora informou que, quando o indivíduo tivesse finalizado, fosse deixado sobre a mesa da sala de atendimento e que encontraria com usuário e seu acompanhante na sala de espera. Ao encontrálos, a pesquisadora se despediu, agradeceu a participação e orientou que o mesmo estava liberado para continuidade do tratamento seguindo a rotina convencional estabelecida no serviço de saúde.

\subsection{Análise estatística}

Foi realizada uma análise descritiva dos dados com distribuições de frequências para os registros das intervenções necessárias obtidos das entrevistas presenciais e online, bem como para o questionário no qual o novo usuário de prótese auditiva avaliou a sua satisfação com o programa de seguimento semipresencial proposto neste estudo.

Para o questionário SADL foram apresentadas as principais medidas resumo (média, desvio padrão, mediana, valor mínimo e valor máximo) por meio da utilização do teste dos postos sinalizados de Wilcoxon para comparar 
4 Métodos

a distribuição dos escores das subescalas do questionário SADL entre os instantes do programa, sendo considerados como momento inicial e término do programa.

O nível de significância adotado foi o de 5\% e o software R versão 3.3.2 (www.r-project.org) foi utilizado nas análises. 


\section{Resultados}




\section{RESULTADOS}

Neste capítulo, serão apresentados os resultados da análise da busca ativa dos indivíduos, das intervenções realizadas nos seguimentos presenciais, das intervenções realizadas nas teleconsultas, da satisfação com o uso da prótese auditiva, do tempo de duração do programa e da avaliação do programa de seguimento semipresencial a novos usuários de prótese auditiva.

Para facilitar a apresentação, este capítulo será dividido em oito partes, a saber:

$\checkmark$ Desfechos da busca ativa e aderência ao programa;

$\checkmark$ Análise descritiva da amostra;

$\checkmark$ Análise descritiva das intervenções necessárias no momento inicial e ao término do programa;

$\checkmark$ Análise descritiva das intervenções necessárias nas teleconsultas;

$\checkmark$ Análise descritiva do uso da prótese auditiva no momento inicial e ao término do programa;

$\checkmark$ Análise descritiva da satisfação com a prótese auditiva por meio do questionário SADL no momento inicial e ao término do programa;

$\checkmark$ Tempo de duração do programa;

$\checkmark$ Análise descritiva da avaliação do programa. 


\subsection{Desfechos da busca ativa}

Os desfechos da busca ativa dos indivíduos, por meio de contato telefônico, são demonstrados na Figura 2.

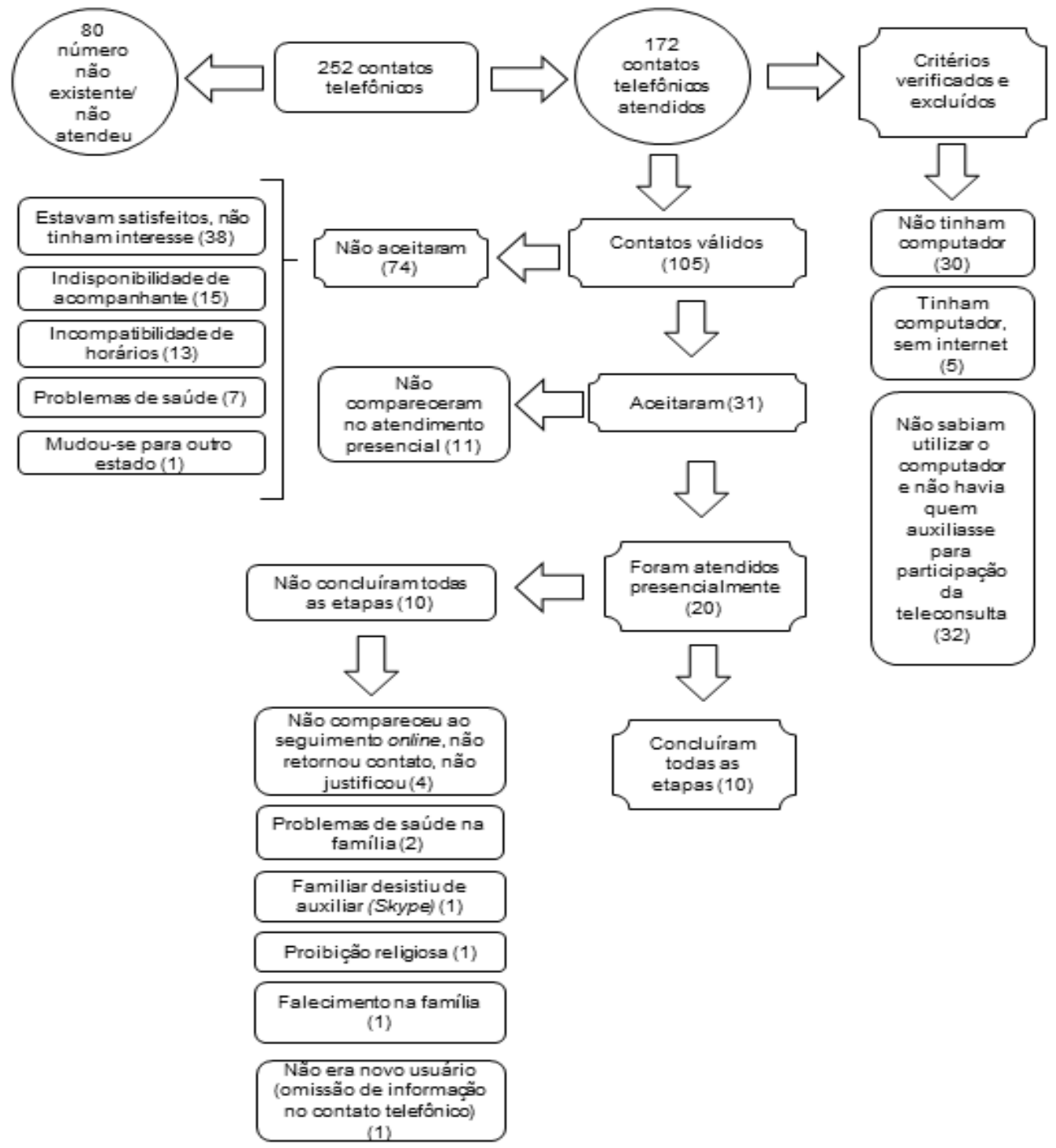

Figura 2 - Desfechos ocorridos na busca ativa dos indivíduos 
Quanto aos impedimentos à aderência ao programa, os resultados são distribuídos na Tabela 1.

Tabela 1 - Distribuição de frequências de indivíduos impedidos de aderir ao programa

\begin{tabular}{lc}
\hline Impedimentos à aderência do programa & N \\
\hline Não tinham familiaridade com a ferramenta proposta (uso do & \\
Skype) & 2 \\
Não comparecimento às sessões de teleconsulta & 2 \\
Problemas de saúde na família & 2 \\
Familiar desistiu de auxiliar nos atendimentos online & 1 \\
Proibição religiosa & 1 \\
Falecimento na família & 1 \\
Não era novo usuário * & 1 \\
\hline TOTAL & 10 \\
\hline NOTA: paciente omitiu a informação no momento da seleção da amostra
\end{tabular}

5.2. Análise descritiva da amostra

Os dados demográficos e audiológicos dos 10 participantes que completaram o programa demonstraram predominância do sexo masculino (7 de 10 participantes) e a média de idade geral foi de 53,7 anos, Tabela 2.

Tabela 2 - Caracterização da amostra segundo idade (anos) e sexo

\begin{tabular}{lccccccc}
\hline & $\mathrm{N}$ & $\%$ & Média & Desvio padrão & Mínimo & Mediana & Máximo \\
\hline Geral & 10 & $100 \%$ & 53.7 & 19.8 & 23.9 & 56.0 & 81.2 \\
F & 3 & $30 \%$ & 46.4 & 30.5 & 23.9 & 34.2 & 81.2 \\
M & 7 & $70 \%$ & 56.9 & 15.4 & 29.5 & 62.5 & 75.8 \\
\hline
\end{tabular}


O nível de escolaridade encontrado variou de Ensino Fundamental

Completo a Ensino Superior Completo, Tabela 3.

Tabela 3 - Distribuições de frequências e porcentagens do Grau de Escolaridade

\begin{tabular}{lcc}
\hline Grau de Escolaridade & $\mathrm{N}$ & $\%$ \\
\hline Ensino Fundamental completo & 3 & 30 \\
Ensino Médio incompleto & 1 & 10 \\
Ensino Médio completo & 3 & 30 \\
Ensino Superior incompleto & 1 & 10 \\
Ensino Superior completo & 2 & 10 \\
\hline TOTAL & 10 & 100 \\
\hline FONTE: Ministério da Educação e Cultura &
\end{tabular}

A análise da ocupação profissional demonstrou que 4 de 10 indivíduos eram aposentados, Tabela 4.

Tabela 4 - Distribuição de frequências e porcentagens da Ocupação Profissional

\begin{tabular}{lcc}
\hline Ocupação Profissional & $\mathrm{N}$ & $\%$ \\
\hline Aposentado & 4 & 40 \\
Do lar & 1 & 10 \\
Estudante (universitária) & 1 & 10 \\
Auxiliar de escritório & 1 & 10 \\
Professor & 1 & 10 \\
Auxiliar administrativo & 1 & 10 \\
Operador de máquina & 1 & 10 \\
\hline TOTAL & 10 & 100 \\
\hline
\end{tabular}

Em relação à utilização do Skype para a realização das cinco teleconsultas, 4 de 10 indivíduos necessitaram do auxílio de um familiar. 
$\mathrm{Na}$ Tabela 5, são apresentadas as características gerais dos 10 indivíduos em relação à necessidade de auxílio para utilização do Skype.

Tabela 5 - Características gerais dos indivíduos em relação ao uso do Skype

\begin{tabular}{ccclc}
\hline Indivíduo & Sexo & Idade & Grau de Escolaridade & $\begin{array}{c}\text { Necessidade de } \\
\text { auxilio para o } \\
\text { uso do Skype }\end{array}$ \\
\hline 1 & Fem. & 24 & Ensino Superior Incompleto & Não \\
2 & Masc. & 30 & Ensino Médio Incompleto & Não \\
3 & Fem. & 34 & Ensino Médio Completo & Não \\
4 & Masc. & 49 & Ensino Médio Completo & Não \\
5 & Masc. & 50 & Ensino Fundamental Completo & Sim \\
6 & Masc. & 62 & Ensino Médio Completo & Sim \\
7 & Masc. & 64 & Ensino Superior Completo & Não \\
8 & Masc. & 68 & Ensino Superior Completo & Não \\
9 & Masc. & 69 & Ensino Fundamental Completo & Sim \\
10 & Fem. & 81 & Ensino Fundamental Completo & Sim \\
\hline
\end{tabular}

Para verificar a influência das variáveis idade e escolaridade em relação à necessidade de auxílio para o uso do Skype, foi realizado o Teste de MannWhitney, Tabela 6.

Tabela 6 - Comparação entre as variáveis idade e escolaridade em relação ao uso do Skype

\begin{tabular}{ccc}
\hline & Necessidade de auxílio para o uso do Skype em relação à \\
\hline \multirow{2}{*}{ Significância } & Idade & Escolaridade \\
\hline
\end{tabular}

Teste de Mann-Whitney 
5.3. Análise descritiva das intervenções necessárias nos atendimentos presenciais

$\mathrm{Na}$ tabela 7 são apresentadas as distribuições de frequências das intervenções presenciais no momento inicial (pré-teleconsulta) e ao término do programa (pós-teleconsulta).

Tabela 7 - Distribuição de frequências das intervenções necessárias nos atendimentos presenciais (início e término do programa)

Explicações do uso do telefone com a prótese auditiva

Explicações sobre a inserção do molde auricular

Explicações da necessidade de trocar o tubo do molde auricular

Explicações sobre a limpeza do molde auricular

Explicação do uso do controle de volume

Encaminhado para o médico otorrinolaringologista

Realização da troca do tubo do molde auricular

Explicação do uso de programas

Orientações relacionadas a zumbido

Explicações sobre a desobstrução do tubo do molde auricular

Explicações sobre o uso do acessório "escova"

Explicações sobre o uso do desumidificador

Explicações sobre a desobstrução do tubo fino

Orientação sobre a importância do uso de duas próteses auditivas

Alteração de até $5 \mathrm{~dB}$ no ganho da prótese auditiva

Realização de audiometria

NOTA: em negrito intervenções primárias
6

$6-1$

6

3

2

2

1

1

0$$
0
$$

1

0

1

0

0

0

1

3

0

0

2

3

1

1 .

1

2




\subsection{Análise descritiva das intervenções necessárias nas teleconsultas}

$\mathrm{Na}$ Tabela 8 são apresentados os dados referentes às intervenções realizadas em cada uma das teleconsultas, a quantidade total de ocorrência das mesmas e o tempo de duração de cada teleconsulta.

Tabela 8 - Distribuição de frequências das intervenções realizadas e tempo de duração (média) de cada teleconsulta

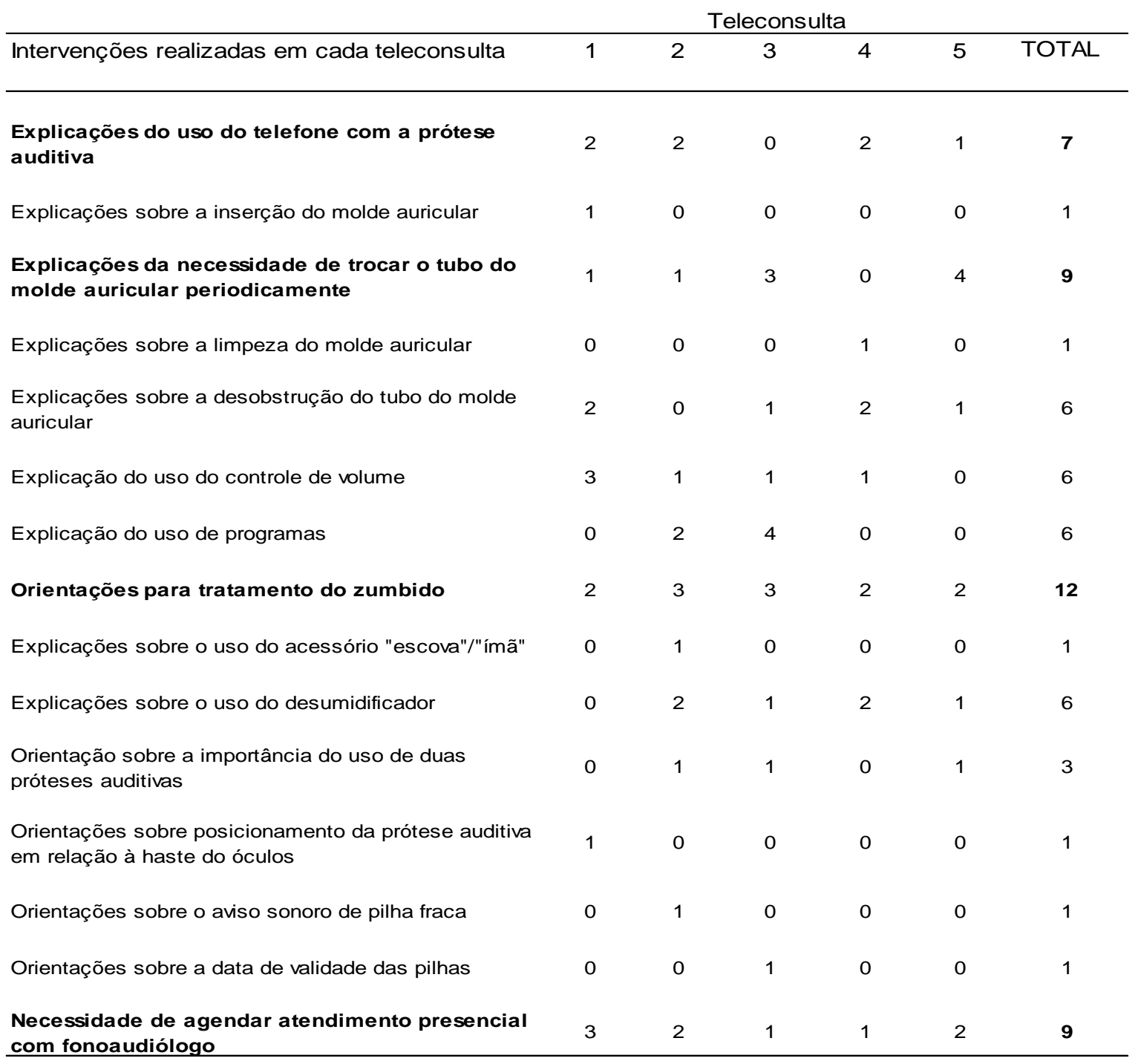

Tempo de duração [média (dp) em minutos] $21(8) \quad 25(16) \quad 24(11) \quad 21(10) \quad 24(10) \quad$ T: $23(11)$ NOTA: em negrito intervenções mais frequentes 
5.5. Análise descritiva do tempo de uso da prótese auditiva

Quanto ao tempo de uso diário da prótese auditiva, o mesmo apresentou variação na $1^{\text {a }}$ Etapa do programa. Ocorreu aumento do tempo de uso na $3^{\text {a }}$ Etapa (considerado término do programa), conforme apresentado na Figura 3.

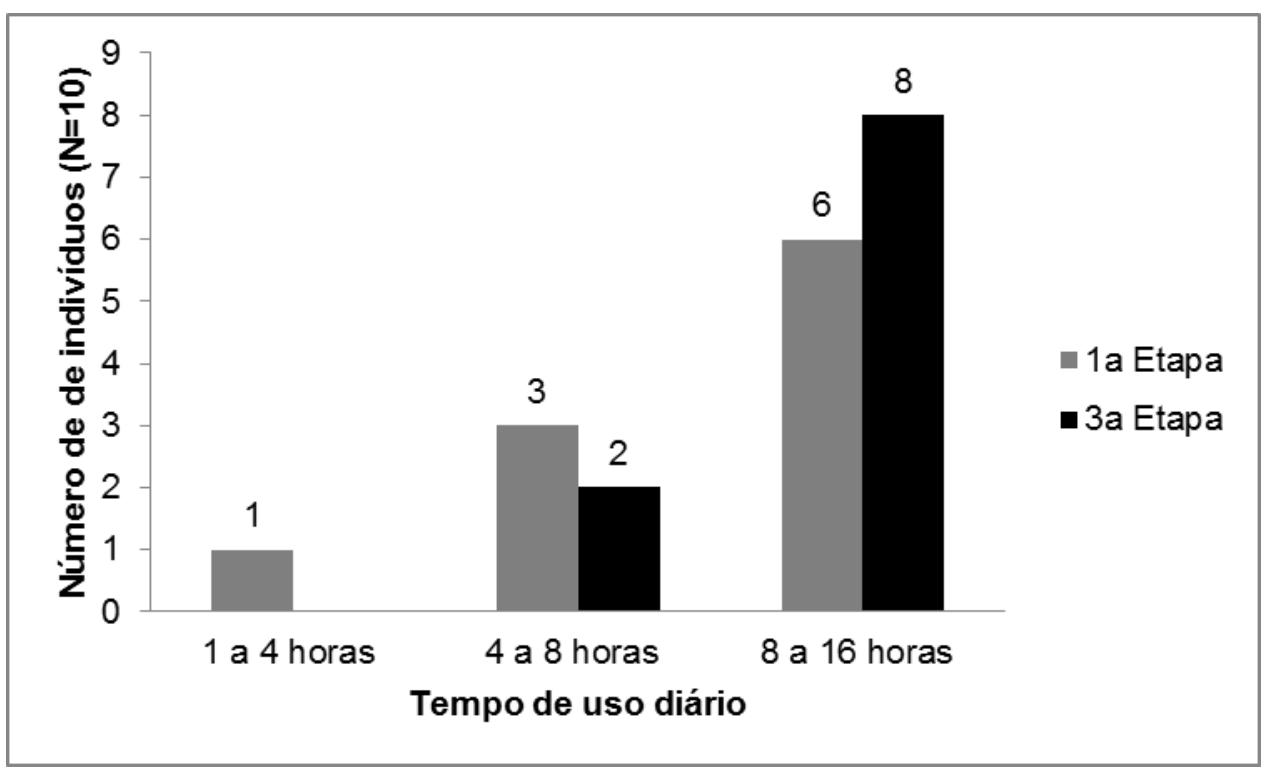

Figura 3 - Distribuição de número de indivíduos segundo tempo de uso diário na $1^{\text {a }}$ e $3^{\underline{a}}$ Etapa do programa

5.6. Análise descritiva da satisfação com a prótese auditiva por meio do questionário SADL no momento inicial e ao término do programa

Os resultados foram analisados considerando a Satisfação Global e suas subescalas. Não houve diferença estatiscamente significante, conforme Tabela 9. 
5 Resultados

Tabela 9 - Estatísticas descritivas para a satisfação global e subescalas do questionário SADL nos dois momentos (pré e pós-teleconsulta)

\begin{tabular}{llccc}
\hline SADL & Medidas & Pré & Pós & P \\
\hline Efeitos & & & & \\
Positivos & média (dp) & $6.25(0.54)$ & $6.57(0.44)$ & 0.1248 \\
& mediana* $^{*}$ & 6.34 & 6.59 &
\end{tabular}

Custos e

Serviços

média $(\mathrm{dp})$

$6.43(0.94)$

$6.73(0.64)$

0.2891

mediana* $^{*}$

6.84

7.00

Fatores

Negativos

média ( $d p)$

$4.30(1.44)$

$5.40(1.94)$

0.2357

mediana* $^{*}$

4.17

6.67

Imagem

Pessoal

média (dp)

$5.13(1.09)$

$5.47(1.48)$

0.5139

mediana*

5.32

6.17

Satisfação

\begin{tabular}{llccc} 
Global & média $(\mathrm{dp})$ & $5.67(0.66)$ & $6.14(0.68)$ & 0.1309 \\
& mediana* $^{*}$ & 5.70 & 6.18 & \\
\hline
\end{tabular}

Teste de Wilcoxon

Legenda: dp: desvio padrão

*mediana: primeiro quartil - terceiro quartil

5.7. Tempo de duração do programa

A Tabela 10 apresenta a duração média do programa em meses, segundo o sexo e amostra total.

Tabela 10 - Medidas descritivas para o tempo de duração (meses) do programa

\begin{tabular}{ccccccc}
\hline & & & \multicolumn{2}{c}{ Desvio } & & \\
& $\mathrm{N}$ & Média & padrão & Mínimo & Mediana & Máximo \\
\hline Fem. & 3 & 5 & 2 & 3 & 5 & 7 \\
Masc. & 7 & 5 & 2 & 2 & 5 & 8 \\
Geral & 10 & 5 & 2 & 2 & 5 & 8 \\
\hline
\end{tabular}


5.8. Análise descritiva da avaliação do programa

Todos os indivíduos que participaram do programa de seguimento semipresencial a novos usuários de prótese auditiva responderam ao "Questionário de avaliação geral do programa". Os resultados da análise descritiva das questões fechadas são apresentados na Tabela 11.

Tabela 11 - Distribuição de frequências e porcentagens das respostas ao questionário de avaliação geral do programa

\begin{tabular}{|c|c|c|c|}
\hline Questão & Resposta & $\mathrm{N}$ & $\%$ \\
\hline As orientações recebidas foram úteis? & Sim & 10 & 100 \\
\hline $\begin{array}{l}\text { Sentiu-se à vontade para esclarecer suas dúvidas } \\
\text { durante os atendimentos online? }\end{array}$ & Sim & 10 & 100 \\
\hline $\begin{array}{l}\text { A quantidade de atendimentos de teleassistência (total } \\
\text { de cinco encontros via Internet) foi o suficiente? }\end{array}$ & Sim & 10 & 100 \\
\hline \multirow{3}{*}{$\begin{array}{l}\text { Em relação ao fato de ter sido orientado pela } \\
\text { profissional fonoaudióloga pelo computador }\end{array}$} & Fiquei mais à vontade pelo computador & 5 & 50 \\
\hline & $\begin{array}{l}\text { Tanto faz, pessoalmente (presencial) ou pelo } \\
\text { computador }\end{array}$ & 4 & 40 \\
\hline & Preferia pessoalmente (presencial) & 1 & 10 \\
\hline $\begin{array}{l}\text { Achou interessante a proposta de receber orientações } \\
\text { online? }\end{array}$ & Sim & 10 & 100 \\
\hline \multirow[t]{2}{*}{$\begin{array}{l}\text { Teve dificuldades em relação à conexão com a } \\
\text { Internet? }\end{array}$} & Um pouco & 4 & 40 \\
\hline & Não & 6 & 60 \\
\hline Voltaria a utilizar esse serviço? & Sim & 10 & 100 \\
\hline Nota da satisfação com o programa proposto & 10 & 10 & 100 \\
\hline
\end{tabular}

Na tabela 12 encontram-se as transcrições das respostas obtidas para a questão aberta de número 8 ("Quais são os aspectos positivos em relação ao atendimento pela internet?"), distribuídas por indivíduo, sexo e idade. 
Tabela 12 - Distribuição das respostas obtidas individualmente para a questão aberta de número 8

\begin{tabular}{cccc}
\hline Indivíduo & \multicolumn{2}{c}{ Transcrições das respostas para a questão aberta de número 8 } \\
\hline 1 & Sexo & Idade (anos) & Quais são os aspectos positivos em relação ao atendimento pela \\
internet?
\end{tabular}

$\mathrm{Na}$ tabela 13 são apresentadas as transcrições das respostas obtidas para a questão aberta de número 9 ("Quais são os aspectos negativos em relação ao atendimento pela internet?"). As respostas encontram-se distribuídas por indivíduo, sexo e idade. 
Tabela 13 - Distribuição das respostas obtidas individualmente para a questão aberta de número 9

\begin{tabular}{|c|c|c|c|}
\hline \multicolumn{4}{|c|}{ Transcrições das respostas para a questão aberta de número 9} \\
\hline Indivíduo & Sexo & Idade (anos) & $\begin{array}{l}\text { Quais são os aspectos negativos em relação ao } \\
\text { atendimento pela internet? }\end{array}$ \\
\hline 1 & Fem. & 24 & $\begin{array}{l}\text { "As falhas de conexão. Possiveis problemas de } \\
\text { entendimento. Quanto a empatia e afetividade creio que } \\
\text { não há diferença em relação ao atendimento } \\
\text { presencial." }\end{array}$ \\
\hline 2 & Masc. & 30 & $\begin{array}{l}\text { "Creio que o aspecto negativo seria o contato físico } \\
\text { entre o médico e o paciente!!" }\end{array}$ \\
\hline 3 & Fem. & 34 & "Nenhum." \\
\hline 4 & Masc. & 49 & $\begin{array}{l}\text { "Quando fica lenta conexão! Em alguns momentos a } \\
\text { presença fica esclarecedor." }\end{array}$ \\
\hline 5 & Masc. & 50 & $\begin{array}{l}\text { "Acredito que não a um aspecto negativo, pois foi muito } \\
\text { prático e rápido." }\end{array}$ \\
\hline 6 & Masc. & 62 & $\begin{array}{l}\text { "Apresentar o aparelho para possível averiguação e } \\
\text { conserto." }\end{array}$ \\
\hline 7 & Masc. & 64 & "Pela proposta, não existiram aspectos negativos." \\
\hline 8 & Masc. & 68 & $\begin{array}{l}\text { "No meu caso por seu usuário de internet e encontrar } \\
\text { variáveis outras, consegui me comunicar sempre. O } \\
\text { Skype muitas vezes fica com mal sinal e pode quebrar o } \\
\text { envolvimento da comunicação. Eu consegui me ajustar. } \\
\text { Hoje temos opções outras como o whats app que pode } \\
\text { ajudar também." }\end{array}$ \\
\hline 9 & Masc. & 75 & "Nenhum. É um avanço o uso da tecnologia." \\
\hline 10 & Fem. & 81 & "Não vejo aspectos negativos." \\
\hline
\end{tabular}

As transcrições das respostas obtidas para a questão aberta de número 11 (“Gostaria de deixar algum comentário?”) são apresentadas por indivíduo na

Tabela 14, segundo sexo e idade. 
Tabela 14 - Distribuição das respostas obtidas individualmente para a questão aberta de número 11

\begin{tabular}{|c|c|c|c|}
\hline \multicolumn{4}{|c|}{ Transcrições das respostas para a questão aberta de número 11} \\
\hline Indivíduo & Sexo & Idade (anos) & Gostaria de deixar algum comentário? \\
\hline 1 & Fem. & 24 & $\begin{array}{l}\text { "Iniciativa muito boa, aumenta a possibilidade de acesso } \\
\text { ao paciente devido a maior disponibilidade de horários e } \\
\text { poder acessar o paciente em seu horário livre." }\end{array}$ \\
\hline 2 & Masc. & 30 & $\begin{array}{l}\text { "Gostaria de agradecer a todos pelo carinho, pela } \\
\text { atenção, pelo bom atendimento, pela compreensão e } \\
\text { pela paciência para comigo!! E que Deus abençoe a toda } \\
\text { a equipe. Meu muito Obrigado!!!" }\end{array}$ \\
\hline 3 & Fem. & 34 & "Agradeço toda a atenção dada à mim." \\
\hline 4 & Masc. & 49 & não respondeu \\
\hline 5 & Masc. & 50 & não respondeu \\
\hline 6 & Masc. & 62 & "Aprendi muito em relação ao aparelho. Foi muito útil." \\
\hline 7 & Masc. & 64 & "Parabéns. Foi muito positivo o atendimento." \\
\hline 8 & Masc. & 68 & $\begin{array}{l}\text { "Sim, quero dizer que me surpreendi com a proposta } \\
\text { oferecida. O acompanhamento, envolvimento e } \\
\text { resultados foram excelentes. Fez com que me sentisse } \\
\text { muito seguro com o programa REOUVIR e com os } \\
\text { profissionais envolvidos. Tenho comentado com amigos } \\
\text { sobre o trabalho de todos e caracterizando esse } \\
\text { programa social de alta relevância. Sem precisar fazer } \\
\text { média, afirmo que dificilmente dou nota } 10 \text { para } \\
\text { pesquisas de satisfação porém, devo reconhecer que }\end{array}$ \\
\hline 9 & Masc. & 75 & $\begin{array}{l}\text { "Excelente atendimento da profissional, tanto presencial } \\
\text { quanto pela internet." }\end{array}$ \\
\hline 10 & Fem. & 81 & $\begin{array}{l}\text { "Fiquei bastante satisfeita com o programa, espero } \\
\text { poder ter essa facilidade outras vezes se possível." }\end{array}$ \\
\hline
\end{tabular}




\section{DISCUSSÃO}

Neste capítulo, são realizadas observações, análise crítica dos resultados e reflexões relacionadas ao desenvolvimento do programa de seguimento semipresencial a novos usuários de prótese auditiva e sua aplicabilidade, dividido em três partes, a saber:

Caracterização e limitação da amostra;

> Intervenções necessárias durante o programa;

Satisfação com o uso da prótese auditiva por meio do questionário SADL no momento inicial e ao término do programa;

Análise e avaliação do programa semipresencial.

\subsection{Caracterização e limitação da amostra}

Inicialmente foram observados os desfechos da busca ativa que resultaram no número reduzido da amostra (Figura 2). O primeiro ponto que chamou a atenção foi em relação ao acesso e à habilidade dos indivíduos com recursos tecnológicos, condição "sine qua non" para o desenvolvimento de programas na área da telessaúde e execução deste projeto de pesquisa. Um aspecto a gerar reflexão é o de que dos 172 contatos telefônicos realizados com êxito, 35 indivíduos informaram que não tinham acesso a computador ou à internet, o que corresponde a $20 \%$ de indivíduos separados por questões 
sócio-econômicas e desigualdades sociais, uma realidade do Brasil. A escassez de literatura apontando a dificuldade do usuário em relação à conectividade não é encontrada, porém, Swanepoel et al. (2010) já identificaram a importância e necessidade deste recurso em locais onde há desigualdade tanto populacional quanto profissional, como na África do Sul.

Outro ponto a ser observado esteve relacionado à perda da amostra por motivos relatados pelos indivíduos referentes às dificuldades de comparecimento ao serviço de saúde, por indisponibilidade de acompanhante ou de horários, problemas de saúde, não comparecimento à consulta agendada, sendo esses aspectos que impactaram negativamente na análise global de projetos de pesquisa, conforme observado em Iwahashi et al. (2013).

Em relação à aderência ao programa, observamos que dos 20 indivíduos que compareceram ao atendimento presencial na primeira etapa, dez concluíram o programa em sua totalidade. O principal motivo da perda de amostra foi o não comparecimento à teleconsulta previamente agendada. Tentou-se realizar contato com esses indivíduos por meio de contato telefônico e/ou envio de mensagens via aplicativo whatsapp, com intuito de verificar se o motivo da ausência era dificuldade relacionada à tecnologia Skype, instrumento utilizado para a realização da teleconsulta durante a segunda etapa do programa. Infelizmente, não houve retorno por parte dos indivíduos para esclarecimento.

A seguir, são apresentadas as observações, análises e reflexões considerando os dez participantes concluintes da amostra. 
A amostra caracterizou-se por indivíduos de ambos os sexos, sendo maior a participação de homens (7 de 10 indivíduos). A média de idade da amostra foi de 53,7 anos (Tabela 2) e o nível de escolaridade variado, sem predominância de nenhum nível (tabela 3).

A maioria dos indivíduos participantes era economicamente ativa (Tabela 4) e foi necessário o auxílio de um acompanhante (familiar) para uso do Skype em 4 de 10 indivíduos (Tabela 5). Este fato foi observado nos participantes acima de 50 anos, com baixo grau de escolaridade, ativos ou aposentados.

A necessidade de auxílio para o uso do Skype pareceu ter mais relação com o grau de escolaridade do que o fator idade (Tabela 6). Contudo, devido ao tamanho da amostra, não é possível afirmar que essa relação é significativa assim como não foi encontrado na literatura estudos de caracterização de amostra na área da teleconsulta para seguimento.

\subsection{Intervenções necessárias durante o programa}

As intervenções necessárias no atendimento presencial foram de ordem primária e secundária. Houve predominância de intervenções secundárias, de orientações e aconselhamentos, relacionados ao uso da prótese auditiva. Boa parte dos indivíduos (6/10) necessitou de reforço na explicação relativa ao uso do telefone e colocação do molde auricular (Tabela 7). Esses achados corroboram com estudos anteriores, como observado em Magalhães e Mondelli 
(2011), Peruzzo et al. (2011) e Iwahashi et al. (2013), que justificaria a necessidade de aumentar a quantidade de seguimentos para que o usuário absorvesse melhor as orientações e aconselhamentos fornecidas pelo profissional.

Ao comparar as necessidades de intervenções presenciais, pré e pósteleconsulta, observou-se que o reforço das orientações realizadas, mesmo à distância, proporcionou ao usuário assimilar as informações necessárias para o uso, motivando-os ao aumento do tempo de uso diário (Figura 3).

Os achados descritos anteriormente convergem com o estudo de Campos e Ferrari (2012) ao considerarem o uso da teleconsulta como um instrumento eficaz para realização do atendimento a usuários de prótese auditiva.

As quatro principais intervenções secundárias na etapa da teleconsulta foram provenientes de dúvidas relacionadas a orientação (Tabela 8). Essas intervenções necessárias foram semelhantes às observadas em Iwahashi et al. (2013).

A intervenção predominante na teleconsulta esteve relacionada ao zumbido, sintoma tão frequente e discutido, que já foi objeto de pesquisa no desenvolvimento de aplicativos e suporte online para promoção de alívio e conforto ao paciente, conforme descreveu Bento e Penteado (2015).

No caso da intervenção relacionada à necessidade de agendamento presencial, não foi possível solucionar algumas das dúvidas expostas pelos 
indivíduos, referentes a desconforto físico com o molde auricular e problemas técnicos relacionados ao funcionamento da prótese auditiva. Esses resultados demonstraram que $\mathrm{o}$ atendimento por teleconsulta não exclui a necessidade de atendimentos presenciais para realizar intervenções primárias.

Tais achados corroboram com o exposto em Bento et al. (2015) os quais afirmam que os profissionais não deveriam apresentar resistência à utilização da teleconsulta, pois o seu uso não descarta a necessidade de atendimentos presenciais.

6.3. Satisfação com o uso da prótese auditiva por meio do questionário SADL no momento inicial e ao término do programa

A satisfação do usuário pela utilização do questionário SADL pôde ser observada neste estudo, mesmo sendo uma amostra reduzida, que o questionário foi um instrumento útil, de fácil aplicação e permitiu a avaliação do programa desenvolvido neste projeto, assim como observado em estudos anteriores que o utilizaram para estabelecimento de condutas e validação de protocolos (Cox e Alexander, 1999; Farias e Russo, 2010; Magalhães e Mondelli, 2011; Laperuta e Fiorini, 2012; Aurélio et al., 2012; Silva et al., 2013; Dell Antonia et al., 2013; Bento et al., 2015; Almeida et al, 2016).

O tempo para a primeira aplicação do questionário SADL foi de 1 a 2 meses do início do uso da prótese auditiva e a reaplicação do mesmo questionário ocorreu após cerca de 6 meses de uso da prótese auditiva a fim 
de se analisar o uso longitudinal, tempo semelhante ao estudo apresentado em Jardim (2009); Laperuta e Fiorini (2012).

A média do escore obtido na escala Satisfação Global pós-teleconsulta foi de 6,1 pontos o que evidenciou um grau satisfação maior do que o grau da normatização dos autores (Tabela 9). Esses achados convergem com os estudos de Farias e Russo (2010); Aurélio et al. (2012) e Silva et al. (2013); demonstrando que a teleconsulta foi tão eficaz quanto a orientação presencial.

De acordo com a análise comparativa entre cada subescala do SADL, observou-se um aumento no escore, sem, contudo, apresentar diferença estatisticamente significante.

Nesta pesquisa, os novos usuários foram beneficiados gratuitamente com as suas próteses auditivas e em todos os indivíduos foi observado 0 sentimento de gratidão que interferiu para o aumento do escore no índice de satisfação, relacionado à subescala Custos e Serviços, assim como considerado em Farias e Russo (2010), bem como em outros vários estudos que abordaram este tópico.

\subsection{Análise e avaliação do programa}

A proposta de inserir a teleconsulta na rotina clínica apoiou-se nas considerações de Wen (2008) que acredita que a telemedicina pode ser ampliada para os diversos serviços de saúde. 
O objetivo principal do questionário utilizado nesse estudo foi coletar informações a respeito do parecer do indivíduo perante o atendimento online para auxiliar na avaliação da aplicabilidade do programa proposto. Houve a necessidade de elaboração de um novo questionário devido à escassez de literatura na área de audiologia e a sugestão de utilização de técnicas qualitativas para avaliar a interação mediada pelo uso da tecnologia, do mesmo modo observado em Campos e Ferrari (2012) e Reginato e Ferrari (2014).

Os aspectos duração e avaliação do programa também foram considerados para a análise geral do programa.

A duração total do programa foi, em média, de 5 meses para ambos os sexos, período concebível para um acompanhamento longitudinal, como igualmente apontado em Laperuta e Fiorini (2012). As variações entre o mínimo e máximo se deram pelas dificuldades do dia a dia (Tabela 10).

Ao considerarmos cada sessão de teleconsulta, o tempo médio de duração foi de 23 minutos, tempo este necessário para esclarecimento, retenção de atenção e da informação. Esse resultado corrobora com os achados de Reginato e Ferrari (2014) ao verificarem tempo de 18,50 a 39 minutos quando realizaram procedimentos via teleconsulta.

Os resultados encontrados quanto à satisfação geral do programa apontam experiências positivas com o apoio da teleconsulta uma vez que todos os indivíduos atribuíram nota máxima e demonstraram-se "totalmente satisfeitos" com o programa desenvolvido. 
Cabe descrever que os pontos positivos mencionados foram relacionados às orientações recebidas terem sido consideradas como úteis; ao usuário ter ficado mais à vontade de se expressar pelo computador; a quantidade proposta foi considerada satisfatória e que voltaria a utilizar o serviço (Tabela 11). Esses resultados foram semelhantes aos descritos por Bento e Penteado (2015) os quais relataram que o uso da telemedicina pode facilitar a comunicação profissional da saúde-paciente.

Ao final do programa houve um espaço com questões abertas para que cada indivíduo apontasse os aspectos que julgassem positivos (Tabela 12), negativos (Tabela 13) e deixassem comentários acerca da experiência com o procedimento adotado (Tabela 14).

Dentre os apontamentos, destacou-se, nos aspectos positivos, a economia, comodidade, agilidade e flexibilidade de horário. Metade dos indivíduos da amostra não referiu nenhum aspecto negativo e dentre os que referiram, as falhas de conexão foram as mais citadas. Apenas um indivíduo mencionou a necessidade do contato físico entre o profissional e o paciente. Esses achados não puderam ser confrontados com a literatura compulsada por não existirem estudos similares, demonstrando assim, o pioneirismo desta pesquisa.

Confirmou-se neste estudo, a afirmativa de Campos e Ferrari (2012), de que a teleconsulta é um modelo de atendimento eficaz que pode ser utilizada em situações nas quais existam dificuldades e/ou impedimentos para a 
realização do atendimento presencial, podendo ser aplicada em um país com extensão continental, tal como o Brasil.

Também foi observado neste estudo que os indivíduos estavam desinibidos para expor as suas dúvidas por meio de chamadas de áudio e vídeo em tempo real, o que promoveu o engajamento nesse processo e resultou em alto grau de satisfação por meio da sua utilização.

O bom uso da telemedicina pode favorecer o sucesso do processo de seleção e verificação da prótese auditiva, seja na etapa de programação, adaptação e verificação das próteses auditivas ou no aconselhamento informativo à distância (Campos e Ferrari, 2012). Podendo ser utilizado em serviços de saúde auditiva em instituições públicas (Penteado et al., 2014; Fonsêca et al. 2015) ou particulares.

Tendo em vista a importância da orientação ao usuário e as dificuldades encontradas para que o mesmo compareça ao local para 0 atendimento presencial, o uso da teleconsulta permitiu a resolução desses problemas sem que o mesmo tivesse que enfrentar a tarefa árdua envolvida com o deslocamento para o local de atendimento.

Frente aos resultados obtidos, sugere-se a aplicação deste modelo de programa semipresencial em outros serviços relacionados à reabilitação auditiva com intuito de propor melhorias, além de considerar a necessidade de maior amostra em diferentes populações para a elaboração de um protocolo específico na área para ser utilizado como guia de boas práticas. 


\section{CONCLUSÕES}

Apesar do reduzido número da amostra desse estudo, concluiu-se que:

- O programa de seguimento presencial a novos usuários de próteses auditivas pôde ser desenvolvido com sucesso;

- Foi possível verificar e confirmar a aplicabilidade do programa;

- As principais dificuldades apresentadas pelos novos usuários se referiram ao uso, cuidados diários e manuseio da prótese auditiva, que independem do contato físico com o profissional;

- A teleconsulta síncrona permitiu a resolução de problemas secundários apresentados pelos usuários;

- A aderência ao programa esteve relacionada ao acesso à tecnologia e à habilidade do indivíduo para lidar com seus recursos;

- O tempo de duração do programa pôde ser flexível e previamente estabelecido entre profissional-usuário;

- Todos os indivíduos apresentaram-se satisfeitos quando analisados pelo questionário SADL e pelo questionário específico do programa. 
8 Anexos 
8 ANEXOS

ANEXO A - Aprovação da CAPPesq

Hospital das Clínicas da FMUSP

Comissảo de Ética para Análise de Projetos de Pesquisa - CAPPesq

\section{PROJETO DE PESQUISA}

Titulo: PROGRAMA DE SEGUIMENTO SEMIPRESENCIAL A NOVOS USUÁRIOS DE PROTESE AUDITINA

Pesquisador Responstivel: Prof. Dr. Ricardo Ferreira Bento

Pesquisador Executante: Eloá Francisco Drobina

Verstäo: 1

Finalidade Académica: Mestrado

Orientador: Prof. Dr. Ricardo Ferreira Bento

Instituiçăe: HCrMUSP

Departamento: OFIALMOLOGIA E OTDRRINOLARINGOLOGIA

\section{PARECER CONSUBSTANCIADO DO CEP}

Reçistro on-line: 12974

NĆmero do Parecer: 940.578

Data da Relatoria: $28 / 01 / 15$

Apresentaça do Projeto: Projeto de mestrado, voltado ac estudo do abandono do uso da prótese auditiva no decorrer do tempo. Os pesquisadores consideram que novos usudrios de prótese auditiva, mesmo participando de atividades de seguimento na rotina clínica, podem nito compreender alguns detalihes que thes foram apresentados e que s.jo essenciais para o uso diario e boa adaptasāo, podendo afetar diretamente a satisfaçāo ao uso da prótese auditiva. A satisfacto é um dos fatores motivadores ao uso e assegura que 0 individuo atravesse o periodo de aclimatizaça e pode ser avallado pelo questionário validado cientificamente chamado Satisfation with Amplification in Daily Life [SADL'u], disponibilizado pelo Hearing Aid Research Lab (HARL, 2008). A maioria dos serviços de "saúde auditiva" oferece um programa de seguimento, porém, nesse processo, existem dificuldades de locomoça, presença de acompanhante, adoecimento que impedem o comparecimento do usuário de prótese auditiva e assim, a continuidade da manutenç̧ăo dos bons resultados obtidos durante a adaptaça inicial. Para minimizar o número de visitas presenciais e ainda assim prestar o atendimento de qualidade, esclarecer dúvidas e garantir o uso efetivo da protese auditiva os pesquisadores pretendem conciliar a telessaúde nessa rotina de acompanhamento por meio do acesso a leternet. Alguns aspectos serao abordados via web pelo aconselhamento informativo que poderá instruir o nowo usudrio quanto aos cuidados

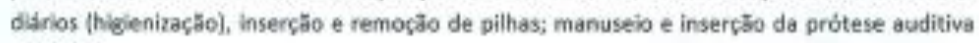
na orelha.

Objetivo da Pesquisa: O objetivo desse estudo é desenvolver um programa de secuimento semipresencial a novos usudirias de prótese auditiva.

Rua Dr. Ovidio Pires de Campos, 225 - Prédio da Administração - 59 andar 


\section{Hospital das Clínicas da FMUSP}

Comissão de Ética para Análise de Projetos de Pesquisa - CAPPesq

Avaliação dos Risços e Beneficlos: Risco minimo, devidamente assinalado no TCLE.

Comentários e Consideraçbes sobre a Pesquisa: 0 estudo poderá trazer informaçb̆es sobre os recursos da telessaúde no seguimento de navos usuárias de próteses auditivas.

Consideraçōes sobre os Termos de apresentaçăo obrigatória: TCLE redigido e apresentado de forma adequada.

Recomendap̧̄es: Sem recomendaçōes adicionais.

Conclusŏes ou Pendencias e Lista de Inadequą̧̋es; o estudo pode ser aprovado.

Situaçăo do Parecer: Aprovado.

Necessita Apreciąăo da CONEP; Não.

Consideraçőes Finais a criterio do CEP: Em conformidade com a Resoluçăo CNS $n^{2}$ 466/12 cabe an pesquisador: a) dosenwolver a prajetn cnoforme delineadn; b) elaborar e apresentar relatórios parciais e final; c)apresentar dados solicitados pelo CEP, a qualquer momento; d) manter em arquivo sob sua guarda, por 5 anos da pesquisa, contendo fichas individuais e todos os demais documentos recomendados pelo CEP; e) encaminhar os resultados para publicaçâo, com os devidos créditos ans pesquisadores associsdos e ao pessal técnico participante do projeta; $f$ justificar perante o CeP interrupçằ do projeto ou a năo publicaçَ̄o dos resultados.

Sao Paulo, 28 de Janeiro de 2015

acpuluanm

Prot. Dr. Alfredo José Mansur Coordenador

Comissöo de Élica para Análise de Projetos de Pesquisa - CAPPesq 
ANEXO B - Termo de Consentimento Livre e Esclarecido

HOSPITAL DAS CLÍNICAS DA FACULDADE DE MEDICINA DA UNIVERSIDADE DE SÃO PAULO-HCFMUSP

TERMO DE CONSENTIMENTO LIVRE E ESCLARECIDO

DADOS DE IDENTIFICAÇÃO DO SUJEITO DA PESQUISA OU RESPONSÁVEL LEGAL

1. NOME:

DOCUMENTO DE IDENTIDADE № : SEXO : .M ( . ) .F.( . )

DATA NASCIMENTO:

№ APTO:

ENDEREÇO CIDADE

BAIRRO: TELEFONE: DDD

CEP:

2.RESPONSÁVEL LEGAL

NATUREZA (grau de parentesco, tutor, curador etc.)

DOCUMENTO DE IDENTIDADE : SEXO: M . F .

DATA NASCIMENTO.: /.......

ENDEREÇO:

№ APTO:

BAIRRO: CIDADE:

CEP: TELEFONE: DDD ( ..)........

\section{DADOS SOBRE A PESQUISA}

1. 1. TÍTULO DO PROTOCOLO DE PESQUISA Programa de seguimento semipresencial a novos usuários de próteses auditivas.

PESQUISADOR : Prof. Dr. Ricardo Ferreira Bento

CARGO/FUNÇÃO: Professor Titular. INSCRIÇÃO CONSELHO REGIONAL №

UNIDADE DO HCFMUSP: Disciplina de Otorrinolaringologia

3. AVALIAÇÃO DO RISCO DA PESQUISA:

$\begin{array}{ll}\text { RISCO MÍNIMO } \square & \text { RISCO MÉDIO } \square \\ \text { RISCO BAIXO } \square & \text { RISCO MAIOR } \square\end{array}$

4.DURAÇÃO DA PESQUISA : ....24 meses 


\section{HOSPITAL DAS CLÍNICAS DA FACULDADE DE MEDICINA DA UNIVERSIDADE}

\section{DE SÃO PAULO-HCFMUSP}

Gostaria de the convidar a participar voluntariamente desse estudo feito pela universidade com novos usuários de próteses auditivas. Temos vários estudos que mostram a importância do senhor(a) receber orientações a respeito do uso das próteses auditivas principalmente no primeiro ano. Caso o senhor(a) aceite participar será preciso que venha após um mês para sua avaliação e, depois disso, a cada 15 dias faremos 5 encontros conversando pela internet. No final o (a) senhor(a) deverá retornar aqui no local para última avaliação. Todas as vezes conversaremos para esclarecer suas dúvidas e ajudá-lo(a) com o uso das suas próteses auditivas.

Os dados ficarão arquivados sem a divulgação do seu nome e você terá a liberdade de esclarecer qualquer dúvida ou de retirar sua autorização quando quiser, como também tem o direito de não participar da pesquisa caso não deseje, sem que isso the traga algum tipo de prejuízo. Continuará inclusive em acompanhamento, se for necessário e caso queira.

Garantia de acesso: em qualquer etapa do estudo, você terá acesso aos profissionais responsáveis pela pesquisa para esclarecimento de eventuais dúvidas. O principal investigador é o Prof. Dr. Ricardo Ferreira Bento que pode ser encontrado no endereço (Av. Dr. Enéas de Carvalho Aguiar, 255 6o andar sala 6167 Telefone(s) 2661.6539 Se você tiver alguma consideração ou dúvida sobre a ética da pesquisa, entre em contato com o Comitê de Ética em Pesquisa (CEP) - Rua Ovídio Pires de Campos, 225 - 5a andar - tel: 2661-6442 ramais 16, 17, 18 - e-mail: cappesq.adm@hc.fm.usp.br

É garantida a liberdade da retirada de consentimento a qualquer momento e deixar de participar do estudo, sem qualquer prejuízo à continuidade de seu tratamento na Instituição.

As informações e conclusões obtidas por meio deste estudo serão utilizadas para discussões junto aos pesquisadores, alunos e profissionais da área de fonoaudiologia e áreas afins, não será revelada a sua identidade. 


\section{HOSPITAL DAS CLÍNICAS DA FACULDADE DE MEDICINA DA UNIVERSIDADE DE SÃO PAULO-HCFMUSP}

Acredito ter sido suficientemente informado a respeito das informações que li ou que foram lidas para mim, descrevendo o estudo" Programa de seguimento semipresencial a novos usuários de prótese auditiva".

Eu discuti com a Fga. Eloá Francisco Drobina sobre a minha decisão em participar nesse estudo. Ficaram claros para mim quais são os propósitos do estudo, os procedimentos a serem realizados, seus desconfortos e riscos, as garantias de confidencialidade e de esclarecimentos permanentes. Ficou claro também que minha participação é isenta de despesas e que tenho garantia do acesso a tratamento hospitalar quando necessário. Concordo voluntariamente em participar deste estudo e poderei retirar o meu consentimento a qualquer momento, antes ou durante o mesmo, sem penalidades ou prejuízo ou perda de qualquer benefício que eu possa ter adquirido, ou no meu atendimento neste Serviço.

Assinatura do paciente/representante legal Data

Assinatura da testemunha

Data / /

para casos de pacientes menores de 18 anos, analfabetos, semi-analfabetos ou portadores de deficiência auditiva ou visual.

(Somente para o responsável do projeto)

Declaro que obtive de forma apropriada e voluntária o Consentimento Livre e Esclarecido deste paciente ou representante legal para a participação neste estudo. 


\section{ANEXO C - Questionário SADL (Mondelli et al., 2011)}

\section{SATISFAÇÃO COM A AMPLIFICAÇÃO NA VIDA DIÁRIA}

Nome: Data de Nascimento:

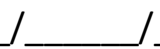

Data de Hoje:

INSTRUÇÕES:

As questões listadas abaixo se referem às suas opiniões sobre o seu aparelho auditivo.

Para cada questão, por favor, circule a letra que responde melhor a questão para você. A lista à direita fornece o significado de cada letra. Lembre-se que suas respostas devem mostrar as suas opiniões gerais sobre o aparelho auditivo que você está usando atualmente ou que tenha usado mais recentemente.

\begin{tabular}{|l|l|}
\hline A & Não \\
\hline B & Muito pouco \\
\hline C & Pouco \\
\hline D & Médio \\
\hline E & Às vezes \\
\hline F & Quase sempre \\
\hline G & Sempre \\
\hline
\end{tabular}

\begin{tabular}{|c|c|c|c|c|c|c|c|c|}
\hline & $\begin{array}{l}\text { O seu aparelho auditivo Ihe ajuda a entender as } \\
\text { pessoas com as quais você fala quando comparada a } \\
\text { época que não usava aparelho auditivo? }\end{array}$ & $A$ & B & $C$ & $D$ & $\mathrm{E}$ & $\mathrm{F}$ & G \\
\hline 2. & $\begin{array}{l}\text { Você fica frustrado quando o seu aparelho auditivo } \\
\text { capta sons que lhe impedem de ouvir o que você } \\
\text { quer? }\end{array}$ & $A$ & $B$ & C & $\mathrm{D}$ & $\mathrm{E}$ & $\mathrm{F}$ & $G$ \\
\hline 3. & $\begin{array}{l}\text { Você está convencido de que a obtenção de seu } \\
\text { aparelho auditivo fazia parte dos seus maiores } \\
\text { interesses? }\end{array}$ & $A$ & $B$ & C & $D$ & $\mathrm{E}$ & $F$ & $\mathrm{G}$ \\
\hline 4. & $\begin{array}{l}\text { Você acha que as pessoas percebem mais a sua perda } \\
\text { auditiva quando você usa o aparelho? }\end{array}$ & $A$ & B & C & $\mathrm{D}$ & $\mathrm{E}$ & $\mathrm{F}$ & G \\
\hline 5. & $\begin{array}{l}\text { O seu aparelho auditivo reduz o número de vezes que } \\
\text { você tem que pedir para as pessoas repetirem? }\end{array}$ & $A$ & B & C & D & $\mathrm{E}$ & $\mathrm{F}$ & G \\
\hline 6. & Você acha que vale a pena usar aparelho auditivo? & A & B & $\mathrm{C}$ & $\mathrm{D}$ & $\mathrm{E}$ & $\mathrm{F}$ & G \\
\hline 7. & $\begin{array}{l}\text { Você se sente incomodado quando necessita aumentar } \\
\text { o volume e ocorre microfonia? }\end{array}$ & A & B & C & $\mathrm{D}$ & $\mathrm{E}$ & $\mathrm{F}$ & G \\
\hline 8. & $\begin{array}{l}\text { Você está contente com a aparência do seu aparelho } \\
\text { auditivo? }\end{array}$ & A & B & C & $\mathrm{D}$ & $\mathrm{E}$ & $\mathrm{F}$ & G \\
\hline & $\begin{array}{l}\text { O uso do seu aparelho auditivo melhora a sua } \\
\text { autoconfiança? }\end{array}$ & A & B & $\mathrm{C}$ & $\mathrm{D}$ & $\mathrm{E}$ & $\mathrm{F}$ & G \\
\hline
\end{tabular}




\begin{tabular}{|c|c|c|c|c|c|c|c|}
\hline 10. O som do seu aparelho auditivo é natural? & A & B & C & D & $E$ & $\mathrm{~F}$ & G \\
\hline $\begin{array}{l}\text { 11. O seu aparelho auditivo é útil na MAIORIA dos } \\
\text { telefones sem amplificador ou caixas de som? }\end{array}$ & A & B & C & D & $\mathrm{E}$ & $\mathrm{F}$ & G \\
\hline $\begin{array}{l}\text { 12. A pessoa que lhe forneceu o aparelho auditivo era } \\
\text { competente? }\end{array}$ & A & B & $\mathrm{C}$ & $\mathrm{D}$ & $\mathrm{E}$ & $\mathrm{F}$ & G \\
\hline $\begin{array}{l}\text { 13. Você acha que usar aparelho lhe faz parecer menos } \\
\text { capacitado? }\end{array}$ & A & B & $\mathrm{C}$ & D & $\mathrm{E}$ & $F$ & G \\
\hline $\begin{array}{l}\text { 14. O custo do seu aparelho auditivo parece razoável para } \\
\text { você? }\end{array}$ & A & B & C & $D$ & $E$ & $F$ & G \\
\hline $\begin{array}{l}\text { 15. Você está satisfeito com a freqüência com a qual seu } \\
\text { aparelho auditivo precisa de reparos? }\end{array}$ & A & B & C & $\mathrm{D}$ & $\mathrm{E}$ & $F$ & G \\
\hline
\end{tabular}

Por favor, responda os itens adicionais.

\begin{tabular}{|l|l|l|l|}
\hline $\begin{array}{l}\text { EXPERIÊNCIA COM } \\
\text { APARELHO ATUAL }\end{array}$ & $\begin{array}{l}\text { EXPERIÊNCIA COM O } \\
\text { APARELHO POR TODA VIDA } \\
\text { (incluindo todos os aparelhos } \\
\text { que já usou) }\end{array}$ & $\begin{array}{l}\text { USO DIÁRIO } \\
\text { DO APARELHO } \\
\text { AUDITIVO }\end{array}$ & $\begin{array}{l}\text { GRAU DE DIFICULDADE } \\
\text { AUDITIVA (sem o aparelho) }\end{array}$ \\
\hline $\begin{array}{l}\text { Menos de } 6 \\
\text { semanas }\end{array}$ & Menos de 6 semanas & $\begin{array}{l}\text { Menos de } 1 \\
\text { hora por dia }\end{array}$ & Nenhum \\
\hline $\begin{array}{l}\text { De 6 semanas a 11 } \\
\text { meses }\end{array}$ & De 6 semanas a 11 meses & $\begin{array}{l}1 \text { a } 4 \text { horas } \\
\text { por dia }\end{array}$ & Leve \\
\hline De 1 a 10 anos & De 1 a 10 anos & $\begin{array}{l}4 \text { a } 8 \text { horas } \\
\text { por dia }\end{array}$ & Moderada \\
\hline Mais de 10 anos & Mais de 10 anos & $\begin{array}{l}8 \text { a } 16 \text { horas } \\
\text { por dia }\end{array}$ & Severa \\
\hline
\end{tabular}

\begin{tabular}{|c|c|}
\hline USO EXCLUSICO DOS & $\mathrm{HO}$ \\
\hline Orelha direita & Orelha esquerda \\
\hline Fabricação_ & Fabricação \\
\hline Modelo_ & Modelo \\
\hline Num série & Num série \\
\hline Data da adaptação_ & Data da adaptação_ \\
\hline Estilo CIC ITC ITE BTE & Estilo CIC ITC ITE BTE \\
\hline CARACTEF & odos que se aplicarem) \\
\hline Microfone Direciona & \\
\hline
\end{tabular}


Microfones Múltiplos Limitação por Compressão

Multicanal TILL

Controle Remoto WDRC

Multiprograma BILL

Sem controle de volume T-Coil

Outros 
8 Anexos

ANEXO D - Registro das intervenções presenciais (adaptado de Goggins

e Day, 2009)

Nome:

Data:

( ) Prótese auditiva com defeito

( ) Alteração de mais de $5 \mathrm{~dB}$ no ganho da prótese auditiva

( ) Mudança de prótese auditiva necessária

( ) Encaminhado para médico otorrinolaringologista

( ) Explicação da necessidade de trocar o tubo do molde auricular periodicamente

( ) Troca do tubo do molde auricular

( ) Alteração no molde auricular

( ) Nova confecção do molde auricular

( ) Explicação sobre a inserção do molde auricular

( ) Alteração de até $5 \mathrm{~dB}$ no ganho da prótese auditiva

( ) Mudança no programa necessária

( ) Explicação do uso de programas

( ) Explicação do uso do telefone com a prótese auditiva

( ) Orientação sobre a importância do uso de duas próteses auditivas (usando apenas uma quando adaptado bilateralmente)

( ) Outros:

*Em negrito: intervenções primárias 
8 Anexos

ANEXO E - Instruções para instalação do software Skype

Nome:

Data:

\section{Programa de seguimento online:}

Instruções para comunicação pela internet:

Para a comunicação siga os seguintes passos:

$1^{\circ}$ passo: Ligue o computador com conexão à internet. Em seguida verifique 0 funcionamento das caixas de som, do microfone e câmera.

$2^{\circ}$ passo: Baixe o aplicativo "SKYPE" da seguinte maneira:

- digite: www.skype.com/pt-br/download-skype/skype-for-computer/

- clique em "baixe o Skype para a área de trabalho do Windows"

- siga as etapas:

Etapa 1: salve o arquivo "SkypeSetup.exe" em seu computador.

Etapa 2: encontre este arquivo de instalação do Skype e clique duas vezes para iniciar a instalação. Siga os passos para concluir a instalação selecionando o idioma português-brasileiro e clique "avançar".

Etapa 3: inicie o Skype, conecte-se com o seu nome skype, sua senha e clique em conectar.

Etapa 4: clique em "começar a usar o Skype".

Etapa 5: adicione o contato eloafono. 
8 Anexos

ANEXO F - Registro das intervenções da teleconsulta (adaptado de

Goggins e Day, 2009)

Nome:

Data:

( ) Explicação da necessidade de trocar o tubo do molde auricular periodicamente

( ) Orientações relacionadas a desobstrução do tubo do molde auricular

( ) Explicação sobre a inserção do molde auricular

( ) Explicação do uso de programas

( ) Explicação do uso do telefone com a prótese auditiva

( ) Orientação sobre a importância do uso de duas próteses auditivas (usando apenas uma quando adaptado bilateralmente)

( ) Orientações para tratamento do zumbido

( ) Necessidade de agendar atendimento presencial com fonoaudiólogo

( ) Outros: 


\section{ANEXO G - Questionário de avaliação geral do programa}

\section{Avaliação final do Programa}

Nome:

Data:

Agradecemos a sua participação no "Programa de seguimento semipresencial a novos usuários de prótese auditiva" e gostaríamos de obter algumas informações por meio deste questionário.

Assinale uma alternativa para cada questão. Pedimos, por gentileza, que responda a todas as questões.

1) As orientações recebidas foram úteis?
( ) sim, muito
( ) sim, o suficiente
( ) um pouco
( ) não

2) Sentiu-se à vontade para esclarecer suas dúvidas durante os atendimentos online?
( ) $\operatorname{sim}$
( ) um pouco
( ) não

3) A quantidade de atendimentos de teleassistência (total de cinco encontros via Internet) foi o suficiente?
( ) $\operatorname{sim}$
( ) não, precisaria de mais
( ) não, poderia ser menos

4) Em relação ao fato de ter sido orientado pela profissional fonoaudióloga pelo computador:

( ) fiquei mais à vontade pelo computador

( ) tanto faz, pessoalmente (presencial) ou pelo computador

( ) preferia pessoalmente (presencial)

5) Achou interessante a proposta de receber orientações online?
( ) $\operatorname{sim}$
( ) mais ou menos
( ) não 
6) Teve dificuldades em relação à conexão com a Internet?
( ) $\operatorname{sim}$
( ) um pouco
( ) não

7) Voltaria a utilizar esse serviço?
( ) $\operatorname{sim}$
( ) não

8) Quais são os aspectos positivos em relação ao atendimento pela Internet?

9) Quais são os aspectos negativos em relação ao atendimento pela Internet?

10) Escala Visual Analógica para a satisfação com o programa proposto

Qual a nota correspondente em relação ao programa proposto por um atendimento presencial, cinco atendimentos oferecidos por teleassistência e o último atendimento presencial?

$$
\text { Nota } 10=\text { muito satisfeito a } 0=\text { totalmente insatisfeito }
$$

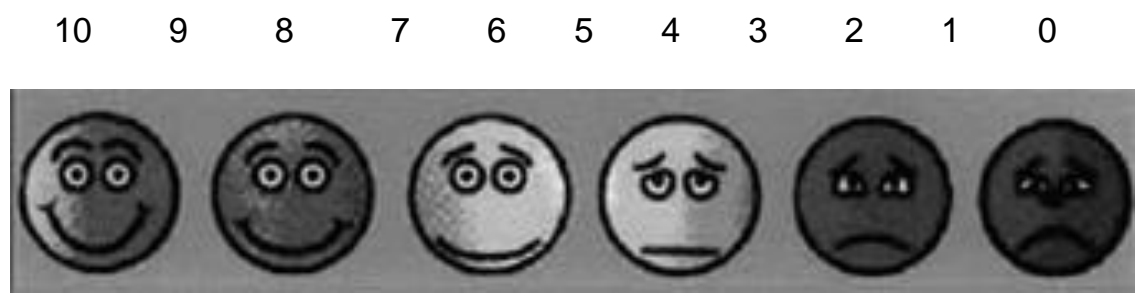

Por gentileza, pontue sua resposta / nota de 0 a 10:

11) Gostaria de deixar algum comentário? 


\section{REFERÊNCIAS}

Almeida MBSK, Torre AAGD, Penteado SP, Gândara M, Bento RF, Kawasaki

TH, Cristina L, Athayde R. Does Questionnaires tell you what your Customers Have in Mind? In: 15 Congresso da Fundação Otorrinolaringologia, 2016, Campos do Jordão, SP. Int Arch. Otorhinolaryngol. 2016; 20(Suppl.1):S101.

Almeida K. Avaliação dos resultados da intervenção. In: Almeida K, lorio MCM. Próteses Auditivas: fundamentos teóricos e aplicações clínicas. 2a Ed. São Paulo: Lovise; 2003: 335-55.

ASHA: American Speech-Language-Hearing Association. Audiologists Providing Clinical Services via Telepractice: Technical Report. [cited 2011 Nov 11]. Available from: http://www.asha.org/docs/html/TR2005-00152.html. ASHA: American Speech-Language-Hearing Association. Telepractice Overview: Providing audiology and SLP services at a distance. [cited 2016 Oct 11]. Available from: https://www.asha.org/Practice-Portal/ProfessionalIssues/Telepractice/

Aurélio FS, Silva SP, Rodrigues LB, Kuniyoshi IC, Botelho MSN. Satisfaction of patients fit with a hearing aid in a high complexity clinic. Braz $J$ Otorhinolaryngol. 2012; 78(5): 69-77.

Bento RF, Penteado SP, Torre AAGD, Gândara M. Telefitting at a Public Rehab Clinic. In: 14 Congresso da Fundação Otorrinolaringologia, 2015, São Paulo. Int Arch Otorrinolaryngol, 2015a:19(Suppl.2):S16. 
Bento RF, Penteado SP, Gândara M, Torre AAGD. Large Improvemens at a Public Rehab Clinic. In: 14ํㅡㄹ Congresso da Fundação Otorrinolaringologia, 2015, São Paulo. Int Arch Otorhinolaryngol. 2015b; 19(Suppl.2):S37.

Bento RF, Penteado SP. Tinnitus Therapy Through Telemedicine (T4). In: 14ํㅡㄴ Congresso da Fundação Otorrinolaringologia, 2015, São Paulo. Int Arch Otorhinolaryngol. 2015:19(Suppl.2):S54.

Brasil. Ministério da Educação e Cultura. LDB - Lei ํo 9394/96, de 20 de dezembro de 1996. Estabelece as diretrizes e bases da Educação Nacional. Brasília:MEC, 1996.

Brasil. Ministério da Saúde. Portaria MS/SAS no 587, de 7 de outubro de 2004. [citado em 19 mar. 2014]. Disponível em: http://portal.saude.gov.br/portal/sas/mac/area.cfm?id area $=824$.

Buriti AKL, Oliveira SHS. Adaptação à prótese auditiva em usuários assistidos pelo Sistema Único de Saúde. Rev Soc Bras Fonoaudiol. 2012; 17(1): 41-6.

Campos PD, Ferrari, DV. Telessaúde: avaliação da eficácia da teleconsulta na programação e adaptação do aparelho de amplificação sonora individual. J Soc Bras Fonoaudiol. 2012; 24(4): 301-8.

Conselho Federal de Fonoaudiologia. Resolução no 366, de 25 de abril de 2009. Dispõe sobre a regulamentação do uso do sistema Telessaúde em Fonoaudiologia. Diário Oficial da União, Brasília DF, 06 mai. 2009. Seção 1:75. 
9 Referências

Conselho Federal de Fonoaudiologia. Resolução no 427, de 1ำ de março de 2013. Dispõe sobre a regulamentação da Telessaúde e dá outras providências. Diário Oficial da União, Brasília, DF, 05 mar. 2013. Seção 1: 158.

Cox RM, Alexander GC. Measuring satisfaction with amplification in daily life: The SADL Scale. Ear Hear. 1999; 20(4): 306-20.

Dell'Antônia SF, Ikino CMY, Filho WC. Degree of satisfaction of patients fitted with hearing aids at a high complexity service. Braz J Otorhinolaryngol., 2013; 79(5): 555-63.

Farias RB, Russo ICP. Saúde auditiva: estudo do grau de satisfação de usuários de aparelho de amplificação sonora individual. Rev Soc Bras Fonoaudiol. 2010; 15(1): 26-31.

Ferrari DV, Blasca WQ. Bernardez GRA, Wen CL. Telessaúde: acesso a educação e assistência em audiologia. In: Bevilacqua MC, Martinez MAN, Balen AS, Pupo A, Reis ACMB, Frota S. Saúde auditiva no Brasil: políticas, serviços e sistemas. São José dos Campos (SP). Editora Pulso; 2010: 189-218.

Ferrari DV, Bernardez GRA, Campos PD. Verificação da prótese auditiva realizada face a face e via teleconsulta: medidas repetidas. Rev CEFAC. 2012; 14(6): 1061-1071.

Fonsêca RO, Brazorotto JS, Balen SA. Telessaúde em Fonoaudiologia no Brasil: Revisão Sistemática. Rev CEFAC. 2015; 17(6): 2033-2043. 
Goggins S, Day J. Efficacy of recalling adult hearing aid users for reassessment after three years within a publicy-funded audiology service. Int $J$ Audiol. 2009; 48: 204-10.

HARL - Hearing Aid Research Laboratories. School of audiology and speechlanguage pathology. Satisfaction with Amplification in Daily Life. 2008. [cited 2011 Aug. 20]. Available from: http://www.memphis.edu/ausp/harl/sadl.htm.

Iwahashi JH, Jardim IS, Bento RF. Results of hearing aids use dispensed by a publicly-funded health service. Braz J Otorhinolaryngol. 2013; 79(6): 681-7.

Jardim IS. Mapeamento visível da fala amplificada na verificação do aparelho de amplificação sonora individual digital. Tese. Faculdade de medicina da Universidade de São Paulo. 2009.

Laperuta EB, Fiorini AC. Satisfação de idosos com os aparelhos de amplificação sonora individuais nos primeiros seis meses de uso. J Soc Bras Fonoaudiol. 2012; 24(4): 316-21.

Lloyd LL, Kaplan H. Audiometric interpretation: a manual of basic audiometry. Baltimore: University Park Press; 1978. p.16-7, 94.

Mondelli MFCG, Magalhães FF, Lauris JRP. Cultural Adaptation of the SADL (Satisfaction with Amplification in Daily Life) questionaire for Brazilian Portuguese. Braz J Otorhinolaryngol., 2011; 77(5): 563-72.

Magalhães FF, Mondelli MFCG. Avaliação da satisfação dos usuários de aparelho de amplificação sonora individual - revisão sistemática. Rev CEFAC. 2011; 13(3): 552-58. 
9 Referências

Oliveira P, Castro F, Ribeiro A. Surdez infantil. Rev Bras Otorrinolaringol. 2002; 68(3): 417-23.

Penteado SP, Bento RF. Reabilitação auditiva por meio da Telemedicina para melhora das políticas públicas no Brasil. Einstein. 2011; 9(1 Pt 1):102-4

Penteado SP, Ramos SL, Battistella LR, Marone SAM, Bento RF. Remote hearing aid fitting: Tele-audiology in the context of Brazilian Public Policy. Int Arch Otorhinolaryngol. 2012; 16(3):371-81.

Penteado SP, Bento RF, Battistella LR, Sooful P. Use of the Satisfaction With Amplification in Daily Life Questionnaire to Assess Patient Satisfaction Following Remote Hearing Aid Adjustments (Telefitting). JMIR Med Inform. 2014; 2(2):e18:1-18.

Penteado SP, Silva TGC, Gândara M, Bento RF, Almeida MBSK, Torre AAGD. Telehealthy at Reouvir's Redisigning our Protocols. In: 15ำ Congresso da Fundação Otorrinolaringologia, 2016, Campos do Jordão, SP. Int Arch Otorhinolaryngol. 2016:20(Suppl.1):S8.

Peruzzo Q, Ceolin D, Quevedo LS. Satisfação de usuários de prótese auditiva. Rev CEFAC. 2015; 17(4):1042-1054.

Reginato TTP, Ferrari DV. Teleaudiology: professional-patient communication in hearing aid programming and fitting via teleconsultation. Audiol Commun Res. 2014; 19(3): 299-309. 
9 Referências

Silva PCB, Silva VB, Aurélio FS. Auditory satisfaction of patients fitted with hearing aids in the Brazilian Public Health Service and benefits offered by the hearing aids. Braz J Otorhinolaryngol. 2013; 79(5): 538-45.

Spinardi-Panis AC, Lopes-Herrera SA, Maximino LP. Aspectos éticos e legais na prática da telessaúde em Fonoaudiologia. Rev CEFAC. 2013, 15(4):10401043.

Swanepoel DW, Clark JL, Kroekemoer D, Hall JW, Krumm M, Ferrari DV, McPherson B, Olusanya BO, Mars M, Russo I, Barajas JJ. Telehealth in Audiology: The need and potential to reach underserved communities. Int $J$ Audiol. 2010; 49(3):195-202.

Wen CL. Telemedicina e Telessaúde - um panorama no Brasil. Rev Inform Públ. 2008; 10(2): 7-15. 